\title{
Functional Neuroimaging in Obsessive-Compulsive Disorder
}

\author{
A. Del Casale ${ }^{a} \quad$ G.D. Kotzalidis ${ }^{a} \quad$ C. Rapinesi ${ }^{a} \quad$ D. Serata ${ }^{a} \quad$ E. Ambrosi ${ }^{a}$ \\ A. Simonetti ${ }^{a}$ M. Pompilia, b S. Ferracuti ${ }^{a}$ R. Tatarellia ${ }^{a}$ P. Girardi ${ }^{a}$ \\ a NESMOS (Neurosciences, Mental Health, and Sensory Organs) Department, School of Medicine and Psychology,

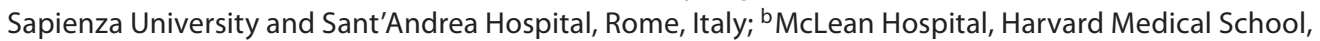 \\ Belmont, Mass., USA
}

\section{Key Words}

Obsessive-compulsive disorder • Functional neuroimaging •

Striatum $\cdot$ Orbitofrontal cortex $\cdot$ Cognitive functions

\begin{abstract}
Background and Aim: Obsessive-compulsive disorder $(O C D)$ is a severe, highly prevalent and chronically disabling psychiatric disorder that usually emerges during childhood or adolescence. This paper aims to review the literature on functional neuroimaging in $O C D$, analysing the reported dysfunctional connectivity in the corticostriatothalamocortical circuitry. Method: This study included papers published in peer-reviewed journals dealing with functional imaging in OCD. Results: Striatal dysfunction, mainly of the caudate nucleus, leads to inefficient thalamic gating, resulting in hyperactivity within the orbitofrontal cortex (intrusive thoughts) and the anterior cingulate cortex (non-specific anxiety). Compulsions consist of ritualistic behaviours performed to recruit the inefficient striatum and neutralise unwanted thoughts and anxiety. Functional neuroimaging findings are discussed against the background of specific cognitive impairments, mainly regarding visuospatial processing, executive functioning and motor speed. Cognitive deficits are partial and specific, matching imaging data. Conclusions: Sev-
\end{abstract}

eral studies have targeted brain regions hypothesised to be involved in the pathogenesis of OCD, showing the existence of dysfunctional connectivity in the corticostriatothalamocortical circuitry. Improvements in spatial resolution of neuroimaging techniques may contribute to a better understanding of the neurocircuitry of OCD and other anxiety disorders.

Copyright $\odot 2011$ S. Karger AG, Basel

\section{Introduction}

Obsessive-Compulsive Disorder: Diagnostic Criteria and Epidemiology

Obsessive-compulsive disorder (OCD) is a common psychiatric disorder affecting more than $1 \%$ of the population worldwide [1]. It is included in the group of anxiety disorders in the DSM-IV [2], but there is considerable debate whether this should continue in the DSM-5 [37]. The hallmark symptoms of OCD include intrusive thoughts (obsessions) as well as ritualistic behaviour (compulsions). The lifetime prevalence of OCD is $2-3 \%$ in the general population [8], with no difference in gender distribution; however, juvenile-onset OCD tends more often to be familial and to have a higher prevalence in

\section{KARGER}

Fax +4161306 1234

E-Mail karger@karger.ch

www.karger.com
(C) 2011 S. Karger AG, Basel

0302-282X/11/0642-0061\$38.00/0

Accessible online at:

www.karger.com/nps
Antonio Del Casale, MD

NESMOS (Neurosciences, Mental Health, and Sensory Functions) Department School of Medicine and Psychology, Sant'Andrea Hospital, Sapienza University Via di Grottarossa 1035-1039, IT-00189 Rome (Italy)

Tel. +39 063377 5675, E-Mail antonio.delcasale@uniroma1.it 
boys $[9,10]$. Its clinical presentation in children and adults is generally similar [2], but comorbidities differ [10]. Its usual onset is in late adolescence or early adulthood, although it may occur from childhood to advanced age [11]. Onset is usually gradual. The course follows a chronic but fluctuating pattern, often related to stressful life events $[12,13]$. Epidemiological surveys suggest that $50 \%$ or more people with OCD have at least one comorbid psychiatric disorder, most commonly an anxiety disorder or unipolar depression. Alcohol abuse/dependence is higher in OCD than in the general population [14].

\section{Functional Neuroimaging Techniques Used to Study OCD}

Functional imaging studies are most useful to clarify the neural substrate underlying the pathophysiology of OCD. Positron emission tomography (PET), single photon emission computed tomography (SPECT), proton magnetic resonance spectroscopy $\left({ }^{1} \mathrm{H}-\mathrm{MRS}\right)$ and functional magnetic resonance imaging (fMRI) are the most frequently used techniques for this purpose.

In the late 1980s, various groups [15-17] carried out PET studies and showed differences between OCD patients and healthy volunteers (table 1). SPECT has been first used in OCD by Machlin et al. [18]. They found alterations in the medial frontal cortex (MFC). This technique uses conventional nuclear medicine planar imaging and a gamma camera to provide three-dimensional rendering (table 2). fMRI first used the paramagnetic contrast agent gadolinium [19], and subsequently noncontrast-based techniques [20-22]. Since then, fMRI has been increasingly employed in psychiatric research and neuroscience. To evaluate brain functions after exposure to stimuli, fMRI is often combined with one or more tasks (i.e. verbal word fluency test, spatial item-recognition tasks, go/no go task, Stroop task, etc.). The use of cognitive or behavioural paradigms as circuitry-specific probes highlights the advantages of fMRI in pursuing this goal.

Studies comparing baseline scans with scans after effective treatment suggest that alterations are OCD state dependent as improvement in symptoms is associated with reestablishing a normal activation pattern [23-25]. Imaging studies of brain response to symptom provocation suggested direct frontal-subcortical circuit involvement in obsessions and compulsions [26-30]. However, these functional alterations could represent only part of a more widespread, latent, prefrontal dysfunction requiring different behavioural challenges to be detected [31, 32]. Our aim has been to review functional neuroimaging studies of OCD, and to analyse the dysfunctional connectivity reported for the corticostriatothalamocortical circuitry (table 3).

\section{Method}

We searched the Medline and PsycINFO databases combining 'obsessive-compulsive disorder' with other keywords like 'positron emission tomography', 'functional magnetic resonance imaging', 'single photon emission computerized tomography' and 'magnetic resonance spectroscopy'. Papers were included if they satisfied standards for adequate methodology, diagnostics (DSM or ICD) and population inclusion (patients with OCD and at least healthy controls). Papers published in peer-reviewed journals dealing with functional imaging in OCD were included. Papers were excluded: if they did not clarify a method for diagnosing OCD, or if OCD was not the principal diagnosis; if severe psychiatric comorbidity was present that could have influenced OCD findings; if the imaging methods were unspecified or inadequately described, and if they were reviews or meta-analyses (but their reference lists were searched anyway). Further papers that did not appear in the above databases were searched from reference lists of papers retrieved.

Data Analysis

Our search yielded a total of 714 papers in the National Library Database/PubMed and 187 papers in PsycLIT as of June 1, 2010; the latter overlapped with the former by more than $95 \%$. A large number of papers were irrelevant and emerged from the search due to its overinclusiveness. By restricting the search for keywords to the title of papers, the yield in PubMed was limited to 82 relevant papers, which we considered too restrictive. We therefore decided to scan all papers found, and eventually kept for analysis and discussion 143 of them that were actually neuroimaging studies, 125 of which were fMRI studies, 6 were PET, 7 were SPECT and 5 were MRS studies. Most irrelevant studies were excluded by simply focusing on their title and abstract; 53 were not immediately excluded from our analysis and our above criteria were applied to exclude them. Thirty-five did not focus on OCD (i.e. the focus lay on other diagnoses and obsessive-compulsive symptoms or OCD were only comorbid), 13 included patients with severe comorbidity, 4 did not use an adequate classification of symptoms, and 1 was excluded for multiple reasons.

The 143 included studies reported data on 755 patients with OCD. Original articles assessed several neuroimaging techniques (MRS: 3.5\%; fMRI: 87.42\%; SPECT: 4.89\%; PET: 4.19\%). Most studies $(81.6 \%)$ compared OCD patients with healthy or other controls; some focused on intragroup comparisons (28.6\%), others compared OCD with other disorders (10.2\%). In OCD patients, these studies showed alterations: in the cingulate cortex (32.6\%); in the ventrolateral prefrontal (10.2\%), dorsolateral prefrontal (32.6\%) and orbitofrontal (51\%) cortices; in other prefrontal areas (10.2\%); in the insular (10.2\%), frontal, parietal and temporal (63.3\%) cortices; in the thalamus (20.4\%); in the cerebellum $(8.2 \%)$; in the striatum (40.8\%) including the caudate nuclei (18.4\%) and the putamen (4\%); in the amygdala (8.2\%); in the hippocampal/parahippocampal region (6.1\%), and in other brain regions (8.2\%). 


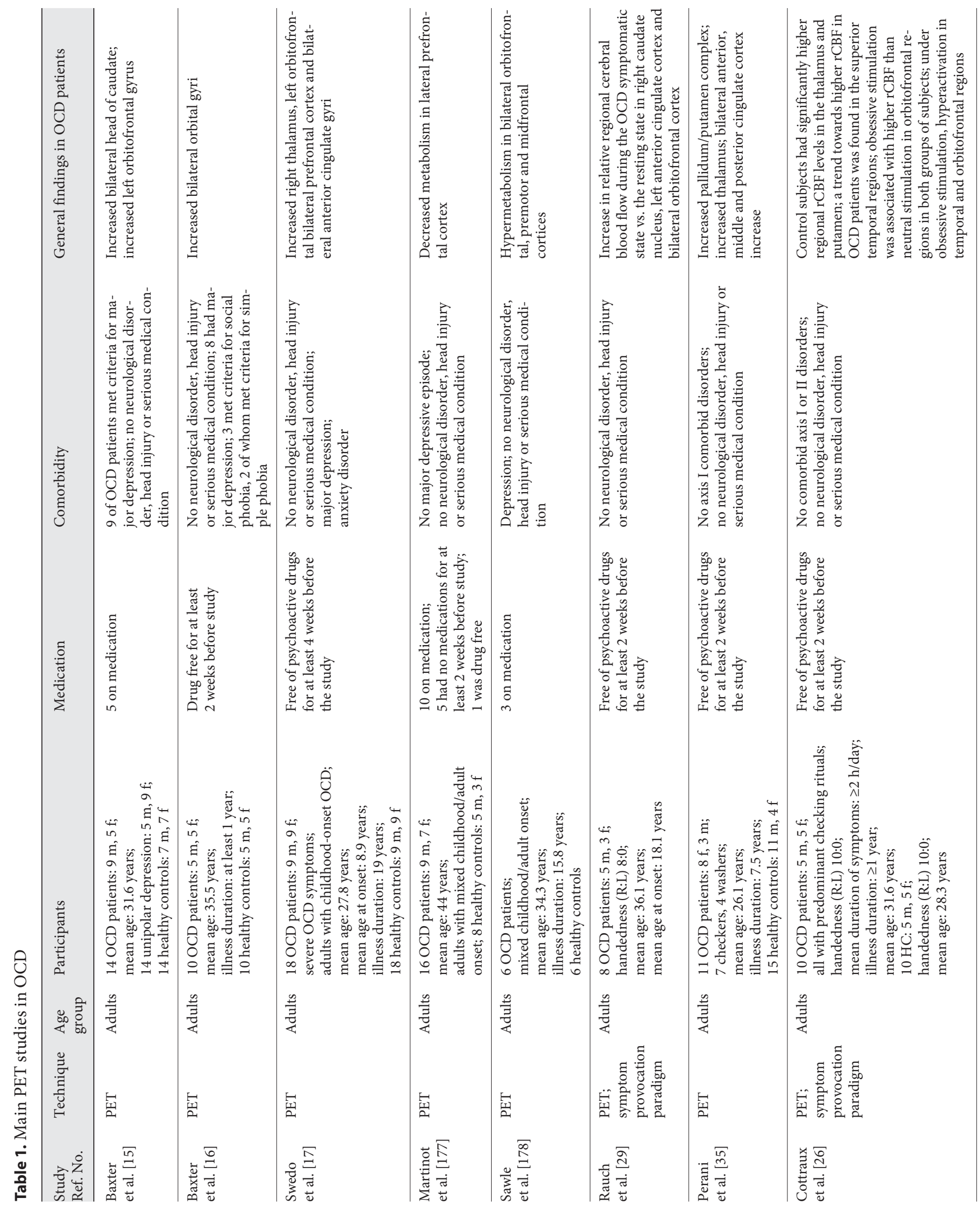




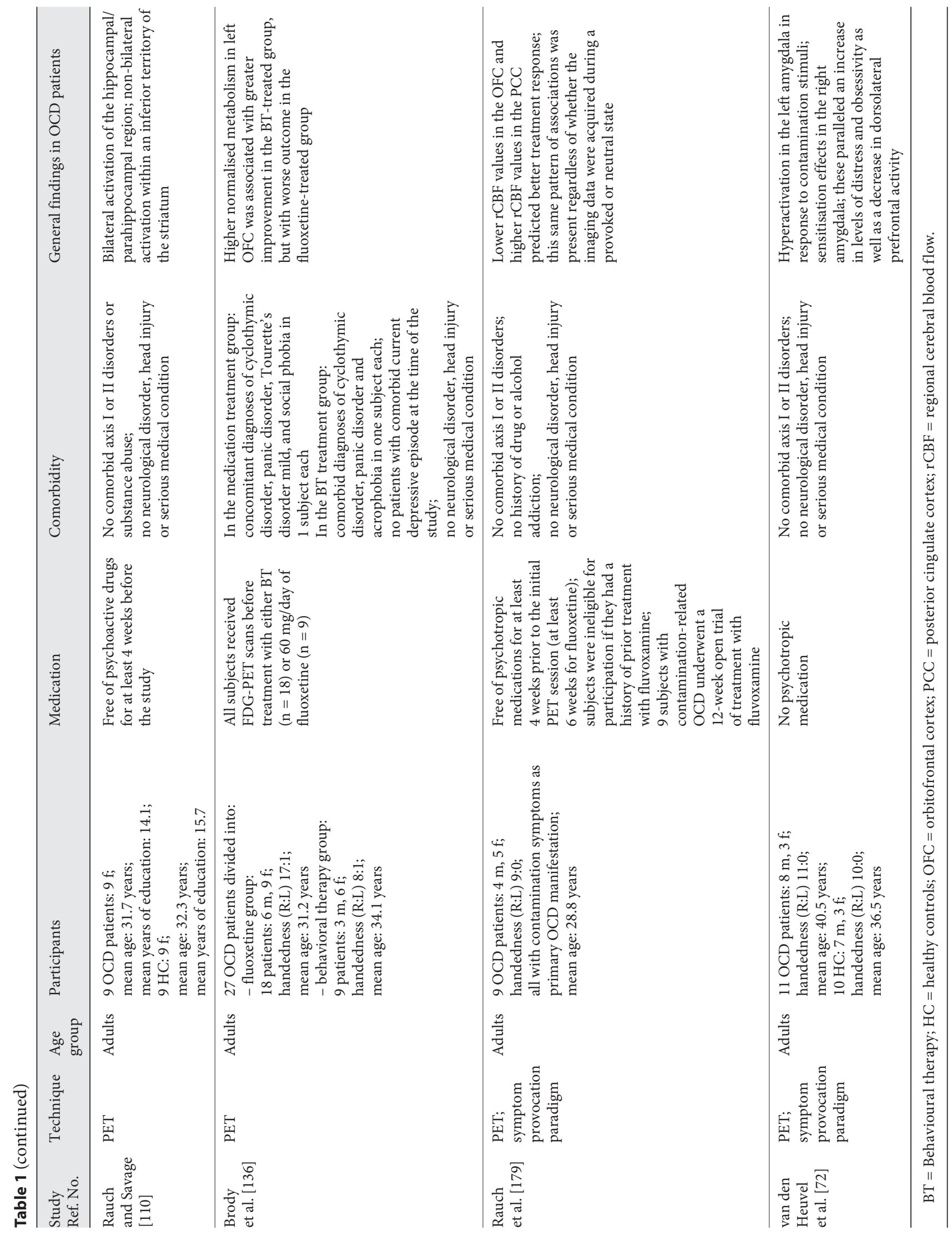




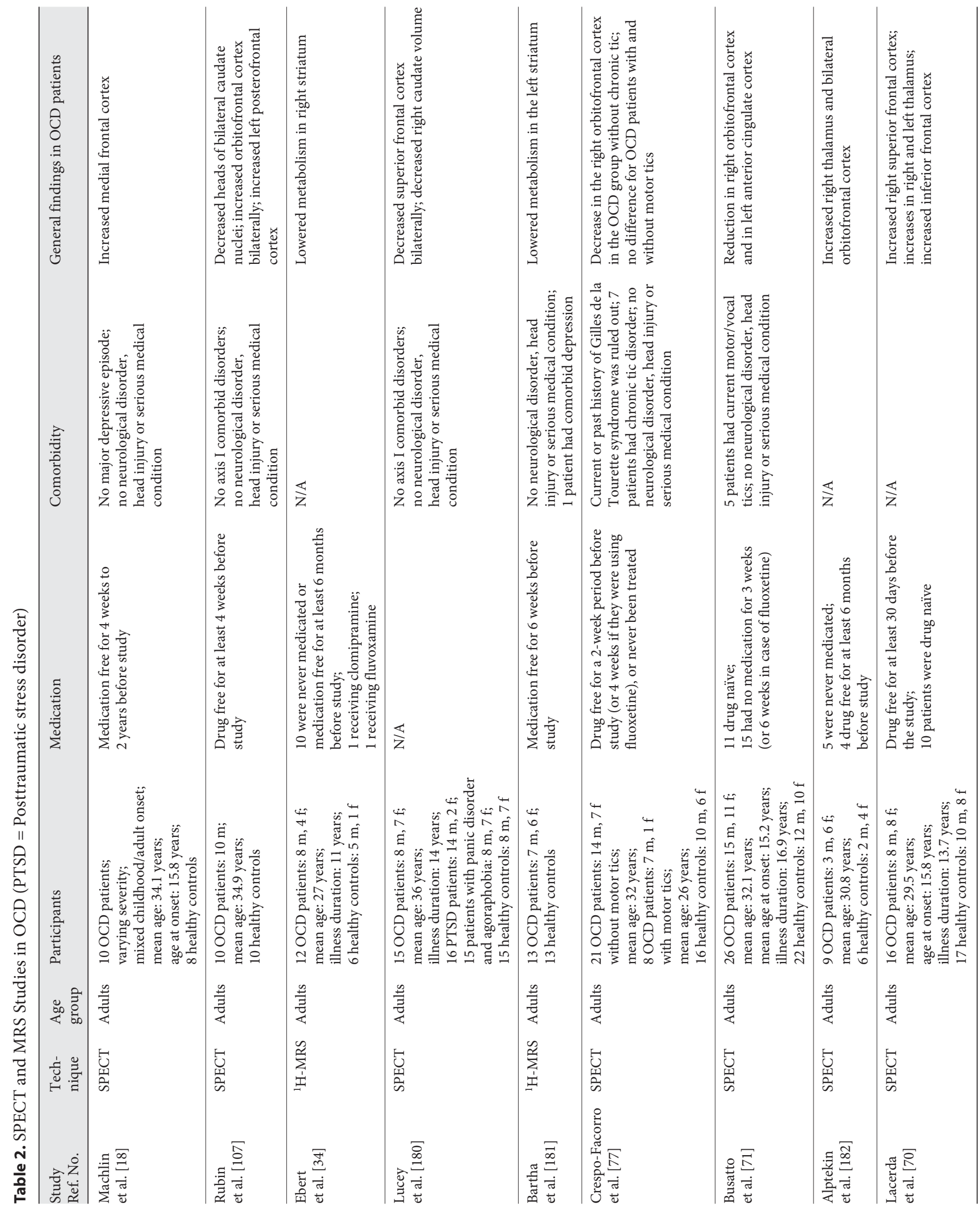




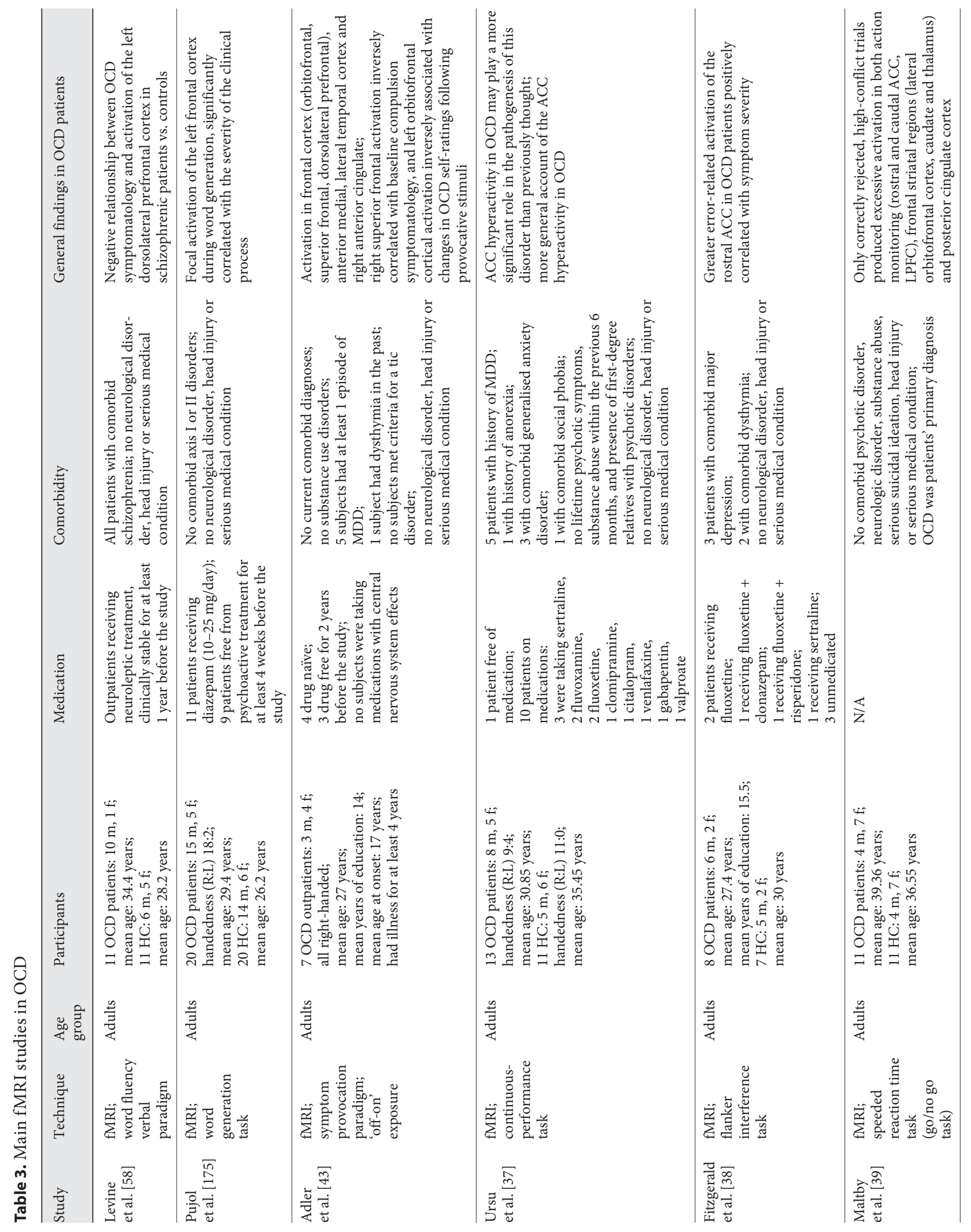




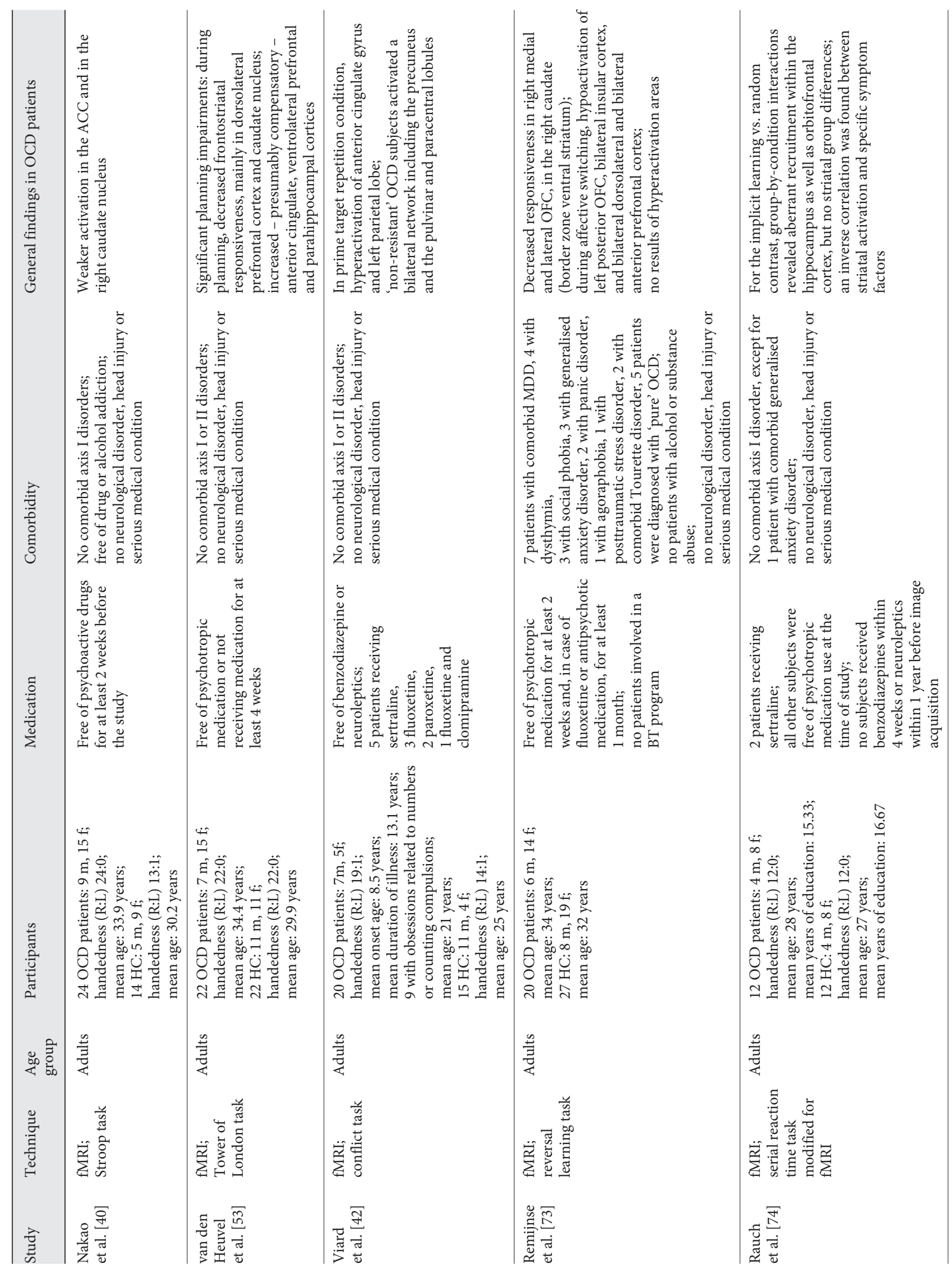




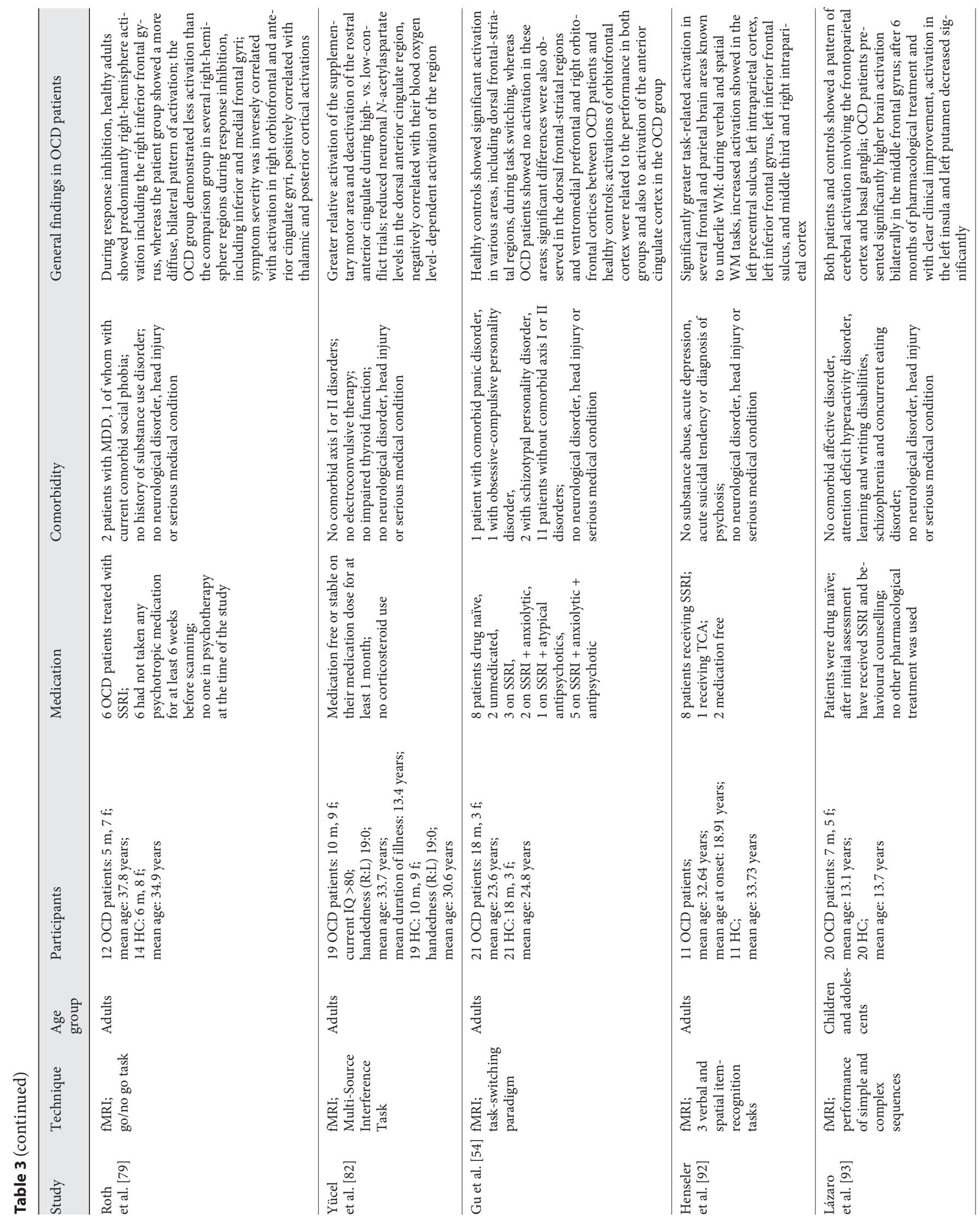




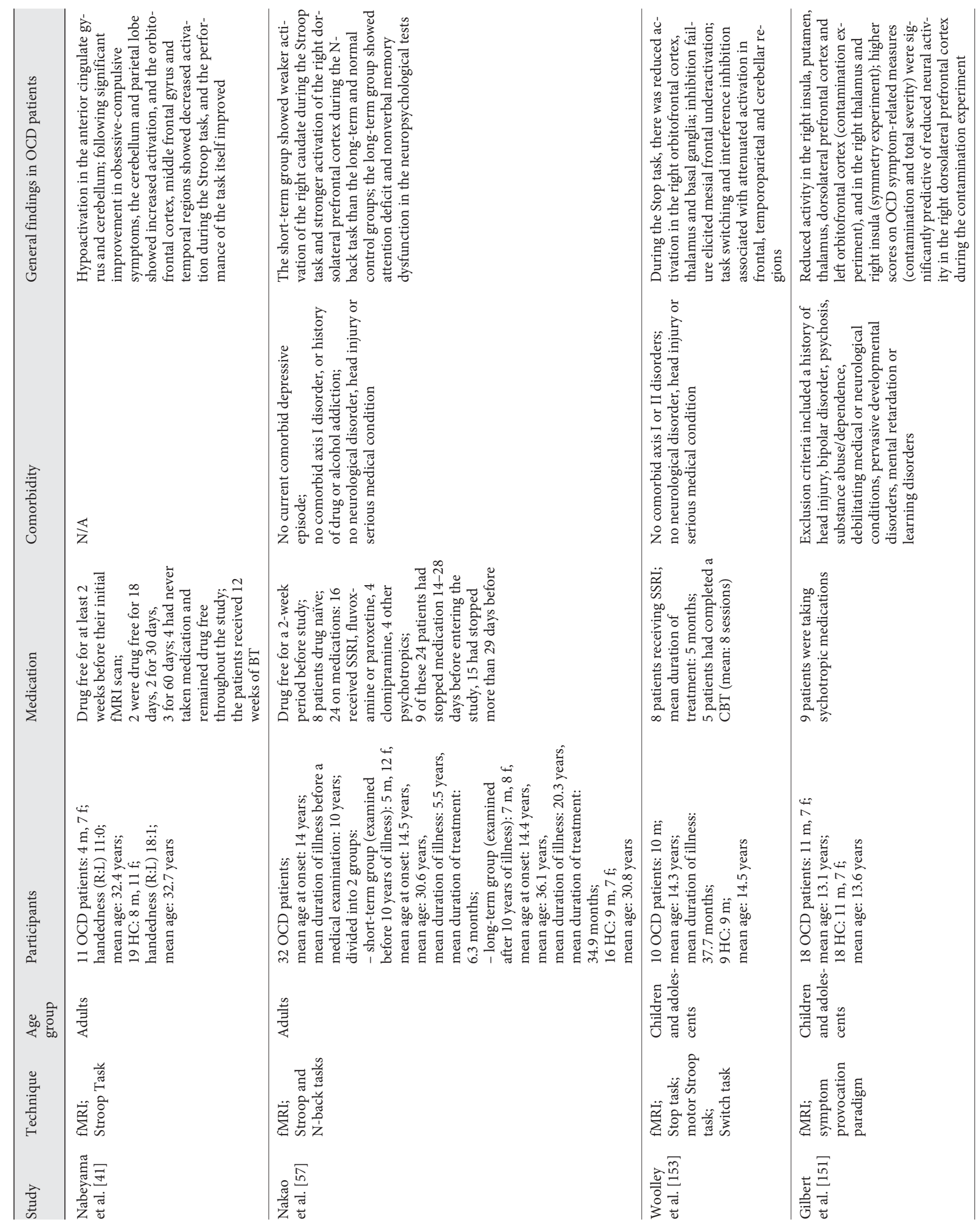




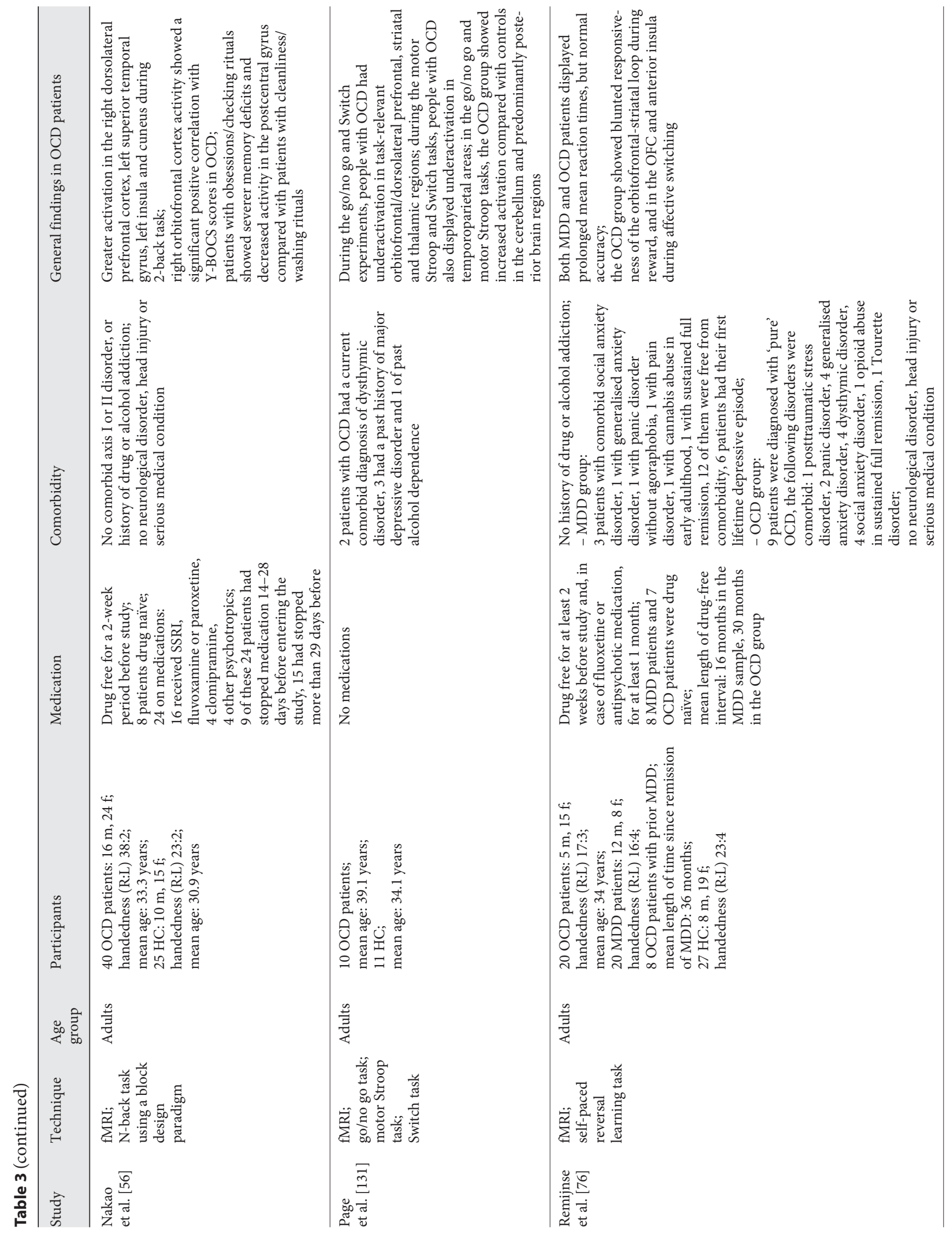




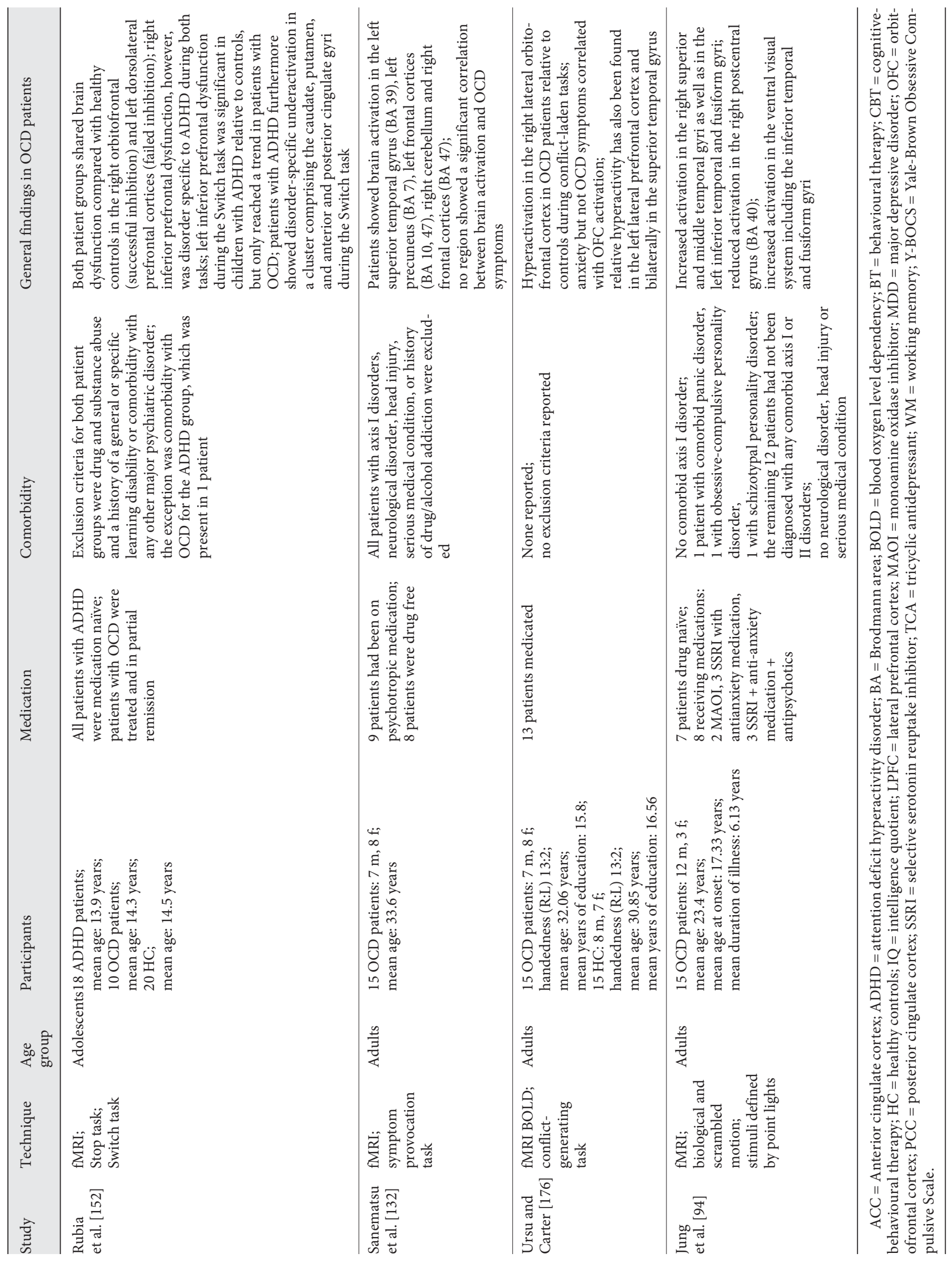


When suspecting population overlap, for example in patients and controls whose details appeared in more than one study by the same research group, we kept the results of the most recent study and with the higher sample size, provided that the same methodology was used. In case the older or smaller-sized studies contained more data than the more recent ones, we kept the older papers.

\section{Results}

\section{Cingulate Cortex Dysfunction}

Structural MRI had shown the involvement of the cingulate cortex in OCD in the context of a more general corticolimbic-striatal circuitry alteration [33]. Functional studies were in the same direction; MRS showed the existence of neuronal loss or impairment in the anterior cingulate cortex [34]. A SPECT study found increased cingulate perfusion ratios relative to the whole brain [18], whereas PET studies found cingulate hypermetabolism in patients with OCD $[17,35]$.

The hyperactivity of the anterior cingulate cortex that has been identified by functional studies has been interpreted as a non-specific index of heightened alertness and anxiety $[17,18]$ as the anterior cingulate cortex is believed to signal to the prefrontal decisional ('executive') cortex anticipatory mismatching between a desired and an actual state and calls for implementation of effective strategies. Hyperactivity in the anterior cingulate cortex is aimed at preventing errors; the anterior cingulate cortex is active during cognitive verification processes that control that everything is going all right, but in OCD patients this activity is not set off when the desired result has been achieved. Despite the fact that the performance of OCD patients is unimpaired in many cognitive tasks [36], anterior cingulate hyperactivity ensues in signalling a conflict when there is none, thus explaining some symptoms like constant doubt and need for repetition although one recognises the correctness of one's own performance. Hyperactivation in the anterior cingulate cortex of OCD patients relative to healthy controls was found in an fMRI study while subjects were tested in a conflict-generating, continuous performance test graded for degree of conflict, but only under the higher-conflict conditions, and this was independent from task-related anxiety [37]. Overall, these findings are consistent with hyperactivity and inability to dampen activity after success of the conflict-monitoring system in OCD.

Fitzgerald et al. [38] subjected OCD patients and healthy controls to fMRI during a flanker interference test that was unable to trigger active OCD symptoms and found greater hyperactivation of the rostral anterior cingulate cortex during conflict in the patient group, which correlated with background OCD symptom severity in the patients. It appears that a basic alteration in conflicting stimulus processing in the anterior cingulate cortex is present in OCD patients even when their symptoms are not manifest.

The role of the cingulate cortex in OCD has been explored by Maltby et al. [39] using a 'go/no go' inhibition task. In this task, the subject is required to abstain from responding to a certain cue while he/she has to respond as fast as possible to another cue that is presented at a much higher frequency, thus constituting a sort of habit that is learned (a prepotent response). The no go cue is a highly conflicting condition. The subject may commit an error either by responding to the no go cue (commission error) or by not responding to the go cue (correct reject). The result was that OCD patients responded with hyperactivation, relative to controls, of both rostral and caudal portions of the anterior cingulate cortex only to no go errors, i.e. when they were required to inhibit a prepotent learned action, lending further support to the hypothesis of hyperactivity of action-monitoring brain areas in OCD. The caudal anterior cingulate cortex is believed to be involved in the recognition of the conflicting nature of a stimulus, whereas the rostral anterior cingulate portion would be linked to the affective response to a conflict. Based on these data, Maltby et al. [39] concluded that in OCD there is a relative inability to inhibit a learned response, and an exaggerated response to it, rather than the incapacity to complete an initiated action.

However, using a different inhibition task, the Stroop colour word naming test, which involves the inhibition of a spontaneous prepotent learned response, both Nakao et al. [40] and Nabeyama et al. [41] found decreased anterior cingulate activation in OCD patients relative to controls during task performance.

Viard et al. [42], using event-related fMRI, compared regional brain activity of healthy controls with adolescents and young adults with childhood-onset OCD. They investigated conflict task performance, involving the presentation of two consecutive and possibly conflicting prime and target numbers. The image dataset of the patients was further analysed according to whether they resisted or yielded to symptoms during the scans. They identified a subregion of the anterior cingulate gyrus where OCD patients showed more activation than healthy controls. Symptom-resisting and symptom-surrendering OCD patients did not differ in activation of the anterior cingulate cortex, but rather bilaterally activated the pre- 
cuneus-pulvinar-paracentral lobule circuitry. It appears from this study that OCD patients abnormally amplify the brain circuitry involved in repetitive visual stimulus discrimination, and that these activations may depend on a patient's ability to resist obsessions [42].

Adler et al. [43] subjected patients with OCD to patient-targeted innocuous and OCD symptom-provoking stimuli (like supposedly infected material to compulsive washers) and found higher activation of the right anterior cingulate cortex under the symptom-provoking condition.

These fMRI findings match those of several previous structural, neuropsychological and functional studies suggesting that dysfunctions of the anterior cingulate cortex $[17,29,44,45]$ play a role in OCD symptomatology. However, the direction and extent of activation depends upon the function explored and the task employed.

\section{Dysfunctions of the Prefrontal Cortex: Ventrolateral}

Prefrontal Cortex and Dorsolateral Prefrontal Cortex

The functions of the lateral prefrontal cortex (LPFC) were studied according to stimulus type (verbal vs. object or spatial) $[46,47]$ and process type (maintenance or manipulation) $[48,49]$. The ventrolateral prefrontal cortex (VLPFC), which includes Broca's area (Brodmann areas, BA, 44, 45 and 47), supports processes that convey, sustain and match information during working memory tasks. The dorsolateral prefrontal cortex (DLPFC), which includes BA 9 and 46, is involved in the processing of spatial and non-spatial information maintained in working memory, i.e. monitoring, manipulation and higher-level planning. A third executive control process, after maintenance in the VLPFC and manipulation in the DLPFC, is run by the anterior prefrontal cortex (frontopolar) including BA 8 and 10 [50].

Models of LPFC interactions with the anterior cingulate cortex may suggest that the LPFC serves to reduce conflict by filtering responses unrelated to task demands, although further research is needed to evaluate the relationship between the LPFC and the anterior cingulate cortex in action monitoring [39]. An increase in VLPFC activity may be a sign of working memory loading (the number of items kept available) and of recovery of abstract rules used for problem solving [51]. Moreover, VLPFC activity is selectively increased during arithmetic computations, mainly when people attempt to resolve a conflict between externally presented answers and internally computed solutions [52]. This network may explain the increased bilateral activity of the VLPFC associated with task load in OCD patients compared with control subjects $[39,53]$. In OCD patients, fMRI under the reversed-contrast condition (such as task repeat minus task switch) showed significant differences in ventromedial prefrontal cortex activities compared with healthy subjects [54].

In an fMRI study, van der Wee et al. [55] found decreased performance only at the highest task level in OCD patients compared with controls during performance of a spatial N-back task. Functional imaging showed similar bilateral DLPFC and parietal cortex activities in both groups, from which the authors concluded that spatial working memory in OCD was not abnormal.

On the other hand, several fMRI studies using the Nback task [56], Stroop and N-back tasks [57] or an off/on exposure paradigm [43] showed greater activation of the DLPFC in OCD patients than in control subjects. It seems that DLPFC activation is greater in recent-onset OCD patients compared with patients with chronic, stabilised disease. In general, OCD patients seem to have some kind of disorder of spatial cognition, attention and non-verbal memory.

In OCD patients, Nakao et al. $[56,57]$ found greater activation in the right DLPFC, left superior temporal gyrus, left insula and cuneus than in control subjects. Furthermore, the patients with cleaning/washing compulsions showed greater activation in the right thalamus and left postcentral gyrus during the N-back task. According to these data, there might be a close relationship between checking rituals and memory-related neuropsychological dysfunction [56, 57].

For several investigators, different brain networks might be involved in checking and washing rituals. Symptom severity and symptom subtypes such as obsessions/checking might affect neuropsychological function and related brain activities.

Levine et al. [58] studied the neurobiological differences between patients with schizophrenia and high or low levels of obsessive-compulsive symptomatology; they did not find significant differences in signal activation of the left DLPFC. However, they found a subgroup of patients with schizophrenia in whom MRI activation of the left DLPFC during a word fluency challenge task was significantly associated with severity of OCD symptomatology. In this subgroup, as OCD symptomatology increased, the activation of the DLPFC decreased.

\section{Dysfunctions of the Orbitofrontal Cortex}

The network involving orbitofrontal cortex (OFC) and striatal structures is important for motivational behaviour, and may be involved in the pathophysiology of OCD 
$[45,59]$. Several functional imaging studies $[26,28,29,43$, $60]$, using symptom provocation designs, have reported orbitofrontal-striatal functional abnormalities in OCD, hypothesised to reflect its role in ritualistic behaviour.

Selective serotonin reuptake inhibitors and dopamine antagonists showed some efficacy in OCD [30,61], and intact transmissions of serotonin (5-hydroxytryptamine) and dopamine have been associated with normal OFC functioning [62] and reward processing in the ventral striatum [63], respectively.

Reward and punishment perception appears to be abnormal in OCD. When experiencing obsessions, patients are always conscious that they are committing a kind of error. Moreover, they give the impression of feeling insufficiently relieved by compulsive behaviour that serves a rewarding goal [59].

A number of neuropsychological tasks addressing particular OFC functions have shown impaired performance in patients with OCD compared with healthy controls [64-67]. Structural neuroimaging studies of OCD showed inconsistent OFC abnormalities in OCD patients compared with healthy controls. OFC volumes were reported to be increased [68] or decreased [69]. Inconsistency was also confirmed by functional imaging studies showing increased $[16,70]$ or decreased [71] OFC activity in OCD patients compared with healthy volunteers. Symptom provocation studies showed increased OFC activity [60] along with both increased $[29,60]$ and decreased [72] caudate activity.

fMRI studies showed decreased responsiveness in the right medial and lateral OFC during a reversal learning task [73], exaggerated OFC activation during implicit sequence learning [74] and after provocative stimuli [43], and asymmetrical patterns of activation in lateral OFC during high-conflict trials [39]. In the first of these studies, the reduction in the number of correct responses relative to healthy controls in OCD patients was paralleled by adequate behaviour on receiving punishment and with regard to affective switching [73]. On reward outcome, patients showed decreased responsiveness in the right medial and lateral OFC as well as in the right caudate nucleus (border area of the ventral striatum) when compared with controls. During affective switching, OCD patients recruited the left posterior OFC, bilateral insular cortex, and bilateral dorsolateral and bilateral anterior prefrontal cortex to a lesser extent than controls [73]. The inverse correlation existing between OCD symptoms and extent of activation in the left OFC appears to suggest that orbitofrontal structures may be active in inhibiting symptom pro- vocation, which is consistent with previous findings $[29,43]$.

During high-conflict trials, fMRI showed in some studies that activation patterns in the lateral OFC were asymmetrical, favouring the left side during both error and correctly rejected, high-conflict trials [39]. Other studies reported that OFC activation was generally bilateral in OCD, but might tend towards increased activation on the left side [75]. It was advanced that the asymmetries observed represented excessive tone in contralateral OFC-caudate projections [39]. However, animal studies support ipsilateral preponderance of OFC-caudate projections [75].

Remijnse et al. [76] analysed 20 unmedicated OCDfree patients with major depressive disorder (MDD), 20 unmedicated MDD-free patients with OCD, and 27 healthy controls. Patients underwent a self-paced reversal learning task according to an event-related design during fMRI. OCD patients showed blunted response of the OFC-striatal loop during reward, and in the OFC and anterior insula during affective switching. This is consistent with differential neural patterns in MDD and OCD in frontal-striatal and paralimbic structures in this task. These findings are consistent with those of several previous structural, neuropsychological and functional studies suggesting that dysfunctions of the OFC $[25,26,29$, $44,45,64,77]$ play a role in OCD symptomatology.

\section{Dysfunctions of the Frontal, Parietal and Temporal \\ Cortices}

Decreased baseline cerebral blood flow in the superior frontal cortex $[60,78]$ may be associated, in OCD patients, with activation after exposure to provocative stimuli $[29,43]$. Activation of the right hemisphere, mostly of the right inferior frontal gyrus, is physiological during response inhibition. In OCD patients this activation is of poorer quality both in the inferior and medial frontal gyri [79]. Adaptive and inhibitory control of behaviour is critically regulated by the MFC, which includes the dorsal anterior cingulate cortex and the supplementary motor area (SMA), which is just about $25 \mathrm{~mm}$ posterior to the dorsal anterior cingulate cortex. Its activity might reflect the processing of response to conflict, as suggested by studies using both flanker-type interference tasks [80] and response inhibition tasks [81]. Abnormally high MFC activity has been a consistent finding in functional neuroimaging studies of OCD. However, the precise regions and the neural alterations associated with this abnormality remain unclear. 
Yücel et al. [82] conducted a cross-sectional study combining volume localised proton MRS and fMRI with a task encompassing inhibitory control processes (the Multi-Source Interference Task), designed to activate the MFC. In this study, compared with controls, OCD patients had a greater relative activation of the SMA and deactivation of the rostral anterior cingulate cortex during high- versus low-conflict (incongruent $>$ congruent) trials. Patients with OCD also showed reduced levels of neuronal $\mathrm{N}$-acetylaspartate in the dorsal anterior cingulate region, which correlated inversely with their blood oxygen level-dependent activation of the MFC.

Hyperactivation of the MFC during high/low-conflict conditions in patients with OCD may be a compensatory reaction to neuronal deficiency in the region. This association may somewhat clarify the nature of inhibitory control deficits that are commonly seen in OCD [82]. Fitzgerald et al. [38] found conflict-related SMA/preSMA activation in controls, but not in OCD patients. As this greater activation in controls was not predicted, the finding is difficult to interpret.

The frontal cortex, especially Broca's language area and the surrounding cortex, is physiologically activated during word generation tasks, mostly when those tasks are phonologically guided (i.e. when subjects are required to generate words beginning with a designated letter) [83-85]. Several studies have confirmed the utility of fMRI in studying frontal activation during this type of verbal fluency in normal individuals [85-89]. In OCD patients, previous neuropsychological studies reported verbal fluency ranging from normal to only mildly altered $[90,91]$.

People showing activation in frontal and parietal brain areas may suffer working memory deficits. Henseler et al. [92] scanned 11 patients and 11 matched controls while they performed three verbal and spatial item-recognition tasks. OCD patients exhibited significantly greater taskrelated activation in several frontal and parietal brain areas involved in working memory. Working memory in OCD patients may be weakened by interference from regions supporting OCD-related processing. On the other hand, working memory disturbances may contribute to the expression of the typical behaviours of OCD patients [92]. It is interesting that hyperactivity of the superior right parietal lobe also correlates with severity of disorder [93].

Some findings may indicate that OCD patients have functional differences related to the perception of biological motion. In OCD patients, alterations in visual association areas were found after exposure to provocative stimuli [43]; abnormal activation was found in temporal areas and in the right postcentral gyrus [94]. Jung et al. [94] studied 15 patients with OCD and 15 age- and IQmatched healthy volunteers. All subjects participated in a biological motion task in which they performed a 1-back conflict task. Patients with OCD showed increased activation in the right superior and middle temporal gyri and in the left inferior temporal and fusiform gyri, as well as reduced activation in the right postcentral gyrus (BA 40), compared with healthy controls. They also exhibited increased activation in the ventral visual system including the inferior temporal and fusiform gyri.

Furthermore, during fMRI while performing a planning task, OCD patients showed increased posterior temporal and parietal cortical activity relative to controls, explained as compensatory mechanisms [53]. Exploratory analysis of individual fMRI scans employing an 'off/on' exposure paradigm showed activation within the lateral temporal cortex and the left medial temporal aspect of the hippocampus and insula in over $50 \%$ of subjects [43]. Aberrant hippocampal recruitment during implicit sequence learning in OCD patients versus healthy controls was reported in an fMRI study using the serial reaction time (SRT) task [74]. The insula is a paralimbic region that plays a role in mediating emotional states including anxiety and disgust. It is possible that clinical improvement after treatment, accompanied by decreased anxiety, leads to decreased activation in this area [93].

Taken together, these findings are consistent with those of a number of earlier structural, neuropsychological and functional studies suggesting that dysfunction of the temporal cortex $[78,95]$, in particular of the anterior temporal cortex $[96,97]$ and of superior regions of the temporal cortex [26], is involved in OCD symptomatology.

\section{Basal Ganglia}

Dopamine-serotonin interplay is important in both the OFC and basal ganglia. Serotonin regulates executive functions in the OFC, like inhibition and flexibility, by preventing possible interfering salient stimuli from being responded to during tasks targeted at other goals [98], thus allowing dopamine-mediated, rewarded behaviour to proceed. Dopaminergic activity in the ventral striatum controls reward processing $[63,73,99]$, whereas striatal serotonergic impairments or OFC lesions cause compulsive behaviour that is inhibited by increasing intrasynaptic serotonin content [100]. Recent SPECT studies reported abnormal dopamine transporter density and irregular $\mathrm{D}_{2}$ receptor binding in the basal ganglia in OCD [101, 102]. 
Basal ganglion disinhibition due to an altered balance between indirect, inhibitory and direct excitatory corticostriatothalamocortical circuits has been advanced to explain OCD symptoms $[45,103]$. There is evidence that the basal ganglia are critical for implicit sequence learning [44]. Patients with Huntington's or Parkinson's disease show poor performance in the SRT task [104], which provides a measure of implicit sequence learning.

\section{Striatum}

Some morphometric studies reported enlarged [69], normal [105] or diminished [106] striatal volumes in OCD patients, whereas functional imaging studies during the resting state showed increased $[16,70]$ or decreased [71] activity in the OFC, and decreased [107] or increased $[16,108]$ activity in the caudate nucleus. PET studies, using an implicit learning task, showed striatal dysfunction in OCD $[109,110]$.

The caudate nucleus projects to the OFC, the anterior cingulate cortex and the thalamus. It has been proposed to play a central role in the corticolimbic-basal gangliathalamus network; network dysfunction may be associated with OCD symptoms [45]. During Stroop test performance, OCD patients showed weaker activation than healthy controls both in the anterior cingulate cortex and in the right caudate nucleus [111] in the absence of neuropsychological impairment. In a subgroup of patients with recent-onset OCD, the same group of researchers found caudate nucleus hypoactivity to be related to attention, and right DLPFC hyperactivity to be related to delayed visual recall $[56,57]$. Higher caudate nucleus activation in OCD patients during conflict processing has been reported in one study [38]. Caudate nucleus hyperactivity in OCD $[15,16,112]$ could be related to excitatory projections from the pre-SMA/SMA region.

Patients with OCD fail to recruit brain systems that are typically responsible for unconscious information processing [44]. This hyperactivation involves the frontal and temporal cortices as well as the cingulate cortex, insula, caudate and lenticular nuclei and amygdala [44], supporting that the neurophysiology of OCD involves hyperactivation of a neural feedback circuit that includes cortical, paralimbic, limbic and striatal structures $[45,79$, $113]$.

Adults with OCD show frontostriatothalamocortical circuitry hypoactivation during response inhibition. The thalamus and related circuitry may play a role in the expression or intensity of OCD symptoms, whereas right frontal subregions may be involved in symptom suppression [79]. In an fMRI study, patients with recent OCD onset showed weaker activation of the right caudate nucleus than healthy controls during Stroop task performance [57].

Both children and adolescent OCD patients, studied by fMRI during the performance of simple and complex sequences and compared with healthy controls, showed significant bilateral hyperactivation in the middle frontal gyrus. After 6 months of pharmacological treatment and with clear clinical improvement, activation in the left insula and left putamen decreased significantly [93]. Other studies reported a decreased responsiveness of dorsal prefrontal-striatal circuits during planning in OCD patients compared with healthy controls, reflecting basal ganglion dysfunction in OCD in implicit learning [109, 114].

Some investigators reported delayed responding [115, $116]$ or reduced performance $[53,117]$ in planning tasks, whereas others found no differences in planning between OCD patients and healthy controls $[118,119]$. Inconsistencies may reflect methodological differences in task implementation, such as mental performance versus the use of a touch screen, or providing feedback versus no feedback $[115,120]$. During planning tasks, fMRI showed that OCD patients failed to recruit dorsal prefrontal-striatal regions as compared with controls [53].

\section{Amygdala}

Among other functions, the amygdala is involved in visual recognition of fearful expressions, whereas the fusiform gyrus is implicated in recognition of facial identity. Use of the fearful versus neutral expression contrast during fMRI allows studying the physiological function of the amygdala. Recent PET findings in normal people suggest that the amygdala has a role in emotional memory [121].

Alternative conceptualisations, however, emphasise the role of the amygdala in rapid threat assessment. The activation of the amygdala in symptom provocation studies may reflect a quantitative versus qualitative distinction related to the magnitude of the threat perceived. It seems that paralimbic-limbic activation, particularly concerning the amygdala, is much more prominent in fMRI studies than in PET investigations of OCD [44].

\section{Cerebellum}

The cerebellum is crucial for movement coordination and motor learning. Recent anatomical and functional studies support its involvement in a variety of cognitive functions such as attention, verbal learning and memory, and cognitive planning [122-125]. 
Nonhuman primates possess pontine projections to the cerebellum from association areas in the prefrontal cortex [126], posterior parietal region [127], parahippocampal region [128] and cingulate gyrus [129]. The existence of a 'cerebellar cognitive affective syndrome' was postulated by Schmahmann and Sherman [130]. This syndrome shows deficits of executive function, visual spatial ability and memory. Such cognitive impairments in patients with cerebellar lesions may be due to alterations to the network linking prefrontal, temporal, posterior parietal and limbic cortices with the cerebellum. Apparently, regions believed to be crucial for interference processes are connected anatomically with the cerebellum. Specifically, fMRI activation was found in OCD in cerebellar regions during a 'focused-attention' task, independent of motor activation, and during a Stroop task [131]. Like the Stroop task, this task requires cognitive control to ignore irrelevant information. Cerebellar hyperactivity [40,132] or hypoactivity [41] was found in OCD patients compared with a group of healthy controls. After symptom improvement, increased cerebellar activation was found [41], even when preceded by hypoactivity [111].

Few studies have described the relationships between obsessive-compulsive symptom improvement, neuropsychological performance and alterations in a wide range of brain activities involving the cerebellum. Metabolic changes in the putamen, cerebellum and hippocampus significantly correlated with symptom improvement [133]. Symptom improvement after behaviour therapy (BT) seems to be significantly associated with increased activation of the cerebellum and parietal lobe, and decreased activation of the OFC, middle frontal gyrus and temporal regions during fMRI while performing the Stroop task. The performance of the task itself improves after BT [41]. Briefly, dysfunctions of the posterior brain regions, especially the cerebellum, are involved in the pathogenesis of OCD; these functions may recover with obsessive-compulsive symptom improvement.

\section{Discussion}

\section{Corticostriatal Pathophysiological Model}

According to a model focusing on the corticostriatothalamocortical circuitry [134], primary OCD alteration lies within the striatum (specifically, the caudate nucleus). This leads to inefficient gating at the level of the thalamus, which results in hyperactivity within the OFC (associated with intrusive thoughts) and hyperactivity within the anterior cingulate cortex (corresponding to non-specific anxiety). Compulsions are viewed as ritualistic behaviours that are performed to recruit the inefficient striatum so as to finally achieve thalamic gating, and consequently neutralise unwanted thoughts and anxiety.

PET and SPECT studies in OCD patients compared with healthy controls consistently found increased activity within the orbitofrontal and anterior cingulate cortices $[17,18,23,135]$, and showed differences in caudate regional activity $[16,18]$. Successful treatment of OCD patients with drugs, BT or their combination is associated with attenuation of abnormal regional brain activity within the OFC, anterior cingulate cortex and caudate nucleus $[17,35,136,137]$. Some evidence suggests that lower pretreatment activity in the OFC predicts better response to serotonergic reuptake inhibitors $[23,28,138$, 139]. Imaging studies showed that regional cerebral blood flow and glucose metabolic rates within the posterior cingulate cortex positively correlate with subsequent response to treatment with fluvoxamine [138] or cingulotomy [140], respectively. Symptom provocation studies with PET [29] or with fMRI [114] have also shown increased brain activity within the anterior/lateral OFC and anterior cingulate cortex in OCD. Cognitive activation studies using PET and fMRI that probed the functional integrity of the striatum in OCD found that OCD patients failed to sufficiently recruit the striatum, which is physiologically activated during completion of the SRT task $[110,114]$. Patients with OCD may utilise frontaltemporal systems as well as explicit information processing strategies to compensate for frontal-striatal dysfunction and corresponding implicit information processing deficits, thereby potentially contributing to the phenomenon of intrusive thoughts [140]. Aberrant hippocampal activation has recently been observed in the absence of deficient striatal recruitment in OCD [74], suggesting the possibility that aberrant hippocampal function plays a primary role in OCD.

The heterogeneity of OCD prompts a decomposition of the OCD phenotype, so to respect the distinct contributions of various symptom dimensions [74, 141, 142]. Hence, general models of OCD are not likely to apply to all cases. Data gathered on the various symptom dimensions or subtypes of OCD call for multifaceted models that reflect these various aspects of the disorder. A fourfactor model of OCD symptom dimensions [143] represents a refinement of the model first presented by Baer [144]. The model by Leckman et al. [143] has now been essentially replicated across an impressive array of subse- 
Fig. 1. Simplified drawing of corticostriatothalamocortical circuitry involved in obsessive-compulsive symptoms (continuous lines), with a hypothetical role for the cerebellum (dashed lines).

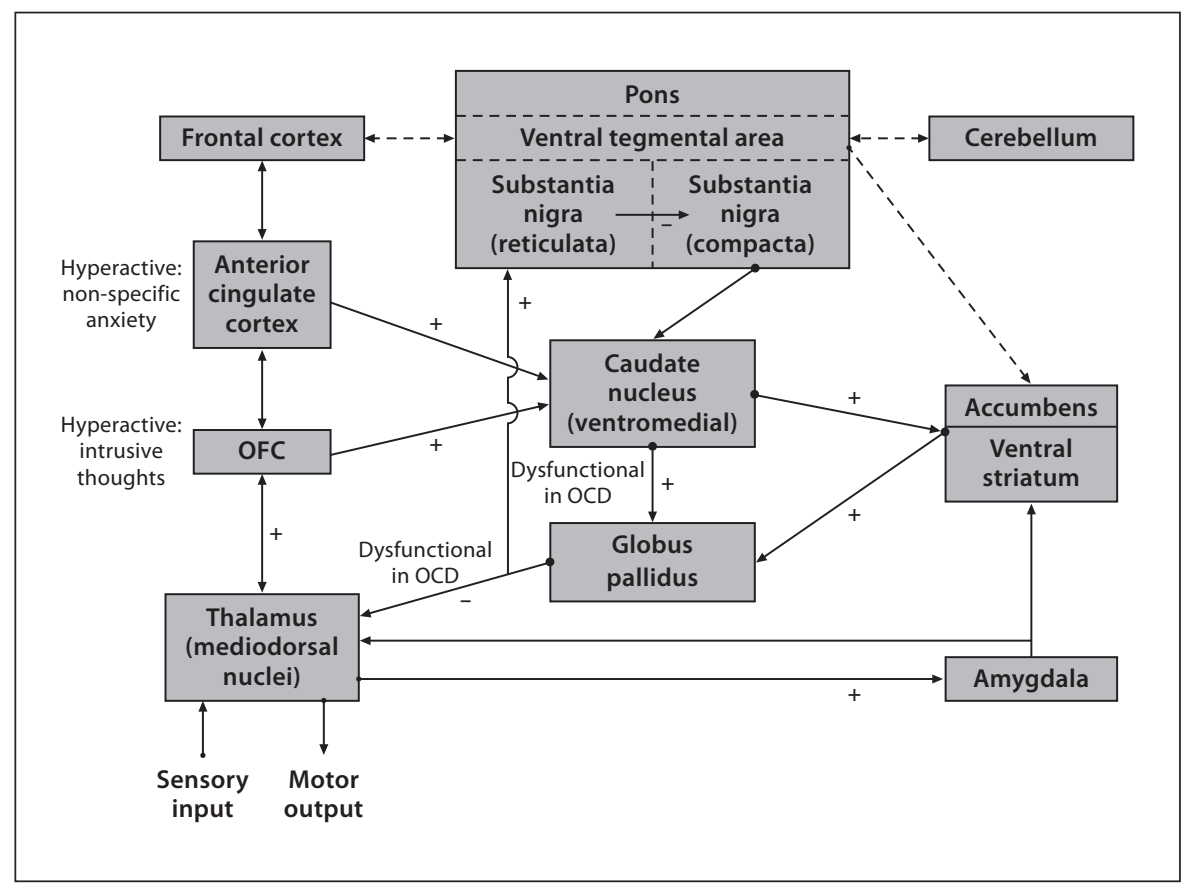

quent studies [12, 117, 145]. This model envisages four dimensions/subtypes, i.e. obsession and checking, symmetry and ordering, cleanliness and washing, and hoarding. Using this four-factor model, investigators have found that symptom dimensions are relatively stable over time [146] and that they are associated with differential response rates to treatment $[117,146]$, possibly reflecting different genetic underpinnings [147-149]. Neuroimaging data suggests that distinct profiles of regional brain function may be associated with each of the various symptom factors $[74,108,150]$. Corticostriatal network dysfunction was also reported in children and adolescents affected by OCD [151, 152]. Woolley et al. [153] studied a group of adolescents by fMRI during the Stop task, an inhibition task similar to a go/no go task, showing in OCD adolescents reduced activation with respect to matched controls in brain areas connected via the inferior and orbital frontostriatothalamic pathways. In the OCD group, stop failures were associated with reduced activation in the mesial and dorsolateral prefrontal cortex, including the anterior cingulate gyrus. During the more cognitive inhibition tasks, the OCD group showed reduced activation in inferior frontal (Switch task) and temporoparietocerebellar regions (motor Stroop and Switch tasks). The findings confirm frontostriatal network abnormalities during motor response inhibition, but in addition show that tasks requiring more cognitive forms of inhibitory control (such as selective and flexible attention) were associated with abnormal functioning in extrafrontal temporal, parietal and cerebellar brain regions.

These findings of frontostriatothalamic hypoactivation during motor inhibition support that a dysregulation of orbitofrontostriatal pathways mediating inhibitory control functions underlies alterations in OCD [153]. They are also in line with reported structural and biochemical abnormalities in paediatric OCD in the frontal lobes, basal ganglia and thalamus $[154,155]$, which have been shown to correlate with severity of OCD symptoms [156]. The complexity of the circuitry involved in OCD (fig. 1) makes heterogeneity possible in that a deficit may be present at any point of the pathway and may trigger dysfunction in the other areas connected.

An issue for future research is whether the dorsal prefrontal-striatal dysfunction is specific to OCD or extends to other neuropsychiatric disorders such as anxiety disorders, basal ganglia disorders, Tourette syndrome and MDD. The latter is characterised by impairment of various executive functions such as verbal fluency and attentional set shifting [157].

However, in MDD, dorsal prefrontal baseline perfusion is decreased rather than increased [158]. In addition, MDD is not associated with striatal alterations [159]. Whereas depressive symptoms frequently cooccur in 
OCD, cognitive deficits in OCD are not associated with comorbid depression [115, 116], suggesting different pathophysiological mechanisms in OCD with respect to MDD [53].

\section{Cognitive Impairments in $O C D$}

Neuropsychological studies $[115,116,160]$ showed cognitive impairments in $\mathrm{OCD}$, mainly regarding visuospatial processing, executive functioning and motor speed. Other cognitive domains appear to remain intact, demonstrating a specific, rather than a general, cognitive deficit.

Executive functioning implies different subdomains of higher-order cognitive functioning. Planning, intended as the ability to achieve a goal via a series of intermediate steps, is an essential component of higher-order cognitive processing such as problem solving. By a neuronal network model, Dehaene and Changeux [161] proposed several hierarchical levels coding for specialised subprocesses of planning such as plan generation, working memory, and internal evaluation and reward. Some subprocesses seem to be relatively independent of task load, whereas other subprocesses are mainly involved at higher levels of planning behaviour.

A test frequently used to probe planning processes is the Tower of London task, adapted from the Tower of Hanoi task $[162,163]$. This task has been used in several studies to investigate planning in healthy controls, using PET [164-167], SPECT [168, 169] and fMRI [170-174]. The results of these imaging studies confirm the involvement of the DLPFC and parietal-occipital regions during planning.

No differences were found in accuracy between OCD patients and controls $[118,119]$. However, when OCD patients provided erroneous responses, they were spending more time than controls in generating alternative solutions or in checking the next response [119]. The results of two studies by Purcell et al. $[115,116]$ - who compared the neuropsychological profiles of patients with OCD, panic disorder and MDD with healthy controls, finding specific deficits of executive functions only in OCD patients, namely spatial working memory, spatial recognition and motor initiation and execution - highlight the importance of task implementation.

Mataix-Cols et al. [117] found impaired performance relative to controls also in subclinical obsessive-compulsive individuals; performance impairment correlated with symptom severity, particularly regarding checking behaviour. Although motor speed was decreased, OCD patients showed a normal ability to manage and execute a sequence of goal-directed moves in a planning task when using a touch screen which provided external validation of ongoing performance. In contrast, when the task had to be performed mentally, OCD patients were significantly impaired [53]. It is still not clear whether impaired executive functioning is a specific OCD trait or whether it is secondary to mood-related or anxiety-related symptoms, but the fact that disorders with such symptoms do not show such impairments $[115,116]$ prompts us to consider the first hypothesis as more likely.

\section{Conclusions}

Several studies have been targeting brain regions hypothesised to be involved in the pathogenesis of OCD, showing the existence of dysfunctional connectivity in the corticostriatothalamocortical circuitry. However, when people with OCD are tested by cognitive tasks exploring domains other than executive functions such as inhibition or flexibility, alterations also in memory function and in structures associated with it come to the fore. Hence, future studies should focus on other brain regions as well to determine their involvement in OCD. Other major foci should comprise the disentangling of OCD from other frequently occurring comorbid conditions like MDD and attention deficit hyperactivity disorder, and the establishment of similarities and differences, as well as the subtyping of OCD according to neuroimaging data, which would help in classifying and treating the disorder better.

Improvements in spatial resolution of neuroimaging techniques may contribute to a better understanding of the neurocircuitry of OCD and other anxiety disorders. However, currently available data allow to conclude that there is an overlap between the pathophysiology of other anxiety disorders and OCD. Hence, on the grounds of the suggestions coming from functional neuroimaging, it would be premature to separate OCD from other anxiety disorders in the DSM-5 and create a new spectrum.

Focusing upon separate symptoms of OCD is not appropriate when investigating alterations in OCD as these symptoms may also be present in other mental disorders, being supported by different biological mechanisms and bearing different psychopathological meanings. Individual symptoms in OCD patients may reveal something about functioning of the OCD while such symptoms are experienced, but they are unable to provide clues to general patterns of OCD brain functioning. Our analysis differently from meta-analyses that by their nature have 
to focus on methodologically similar studies, thus limiting the number of includible studies - shows that patients with OCD have some consistent hyper- or hypoactivations underlying the true nature of brain circuitry alterations in OCD, whereas inconsistencies are more likely to reflect heterogeneity within the context of different $\mathrm{OCD}$ subtypes that should be addressed by future studies focusing on clinically homogeneous populations according to Leckman's subtypes [143].

\section{Acknowledgements}

We acknowledge the aid provided by the librarians of the School of Medicine and Psychology of Sapienza University, Ms. Mimma Ariano, Ms. Tiziana Mattei and Ms. Felicia Proietti for the localisation of relevant literature.

\section{Disclosure Statement}

M.P. has served as a consultant to, or was engaged in research collaborations with Eli Lilly and Organon Corporations in Italy. S.F. has in the past 3 years participated on the advisory boards of Pfizer and Lilly and received honoraria from Lilly, Bristol-Meyers Squibb, Sigma Tau, Schering and Pfizer. P.G. has in the past 3 years received research support from Lilly and Janssen, has participated on the advisory boards of Lilly, Organon, Pfizer and Schering, and received honoraria from Lilly and Organon. R.T. has in the past 3 years participated on the advisory boards of Schering, Servier and Pfizer, and received honoraria from Schering, Servier and Pfizer.

All other authors of this paper have no relevant affiliations or financial involvement with any organisation or entity with a financial interest in, or financial conflict with, the subject matter or materials discussed in the manuscript. This includes employment, consultancies, honoraria, stock ownership or options, expert testimony, grants or patents received or pending, or royalties.

\section{References}

1 Rasmussen SA, Eisen JL: The epidemiology and differential diagnosis of obsessive compulsive disorder. J Clin Psychiatry 1994; 55(suppl):5-10, discussion 11-14.

2 American Psychiatric Association: Diagnos tic and Statistical Manual of Mental Disorders (DSM-IV). Washington, American Psychiatric Association, 1994.

-3 Hollander E: Obsessive-compulsive spectrum phenomena and the DSM-V develop mental process. CNS Spectr 2008;13:107108.

$\checkmark 4$ Hollander E, Braun A, Simeon D: Should OCD leave the anxiety disorders in DSM-V? The case for obsessive compulsive-related disorders. Depress Anxiety 2008;25:317329.

$\checkmark 5$ Mataix-Cols D, Pertusa A, Leckman JF: Issues for DSM-V: how should obsessive-compulsive and related disorders be classified? Am J Psychiatry 2007;164:1313-1314.

$\checkmark 6$ Regier DA: Obsessive-compulsive behavior spectrum: refining the research agenda for DSM-V. Psychiatry Res 2009;170:1-2.

$\checkmark 7$ Storch EA, Abramowitz J, Goodman WK: Where does obsessive-compulsive disorder belong in DSM-V? Depress Anxiety 2008;25: 336-347.

$\checkmark 8$ Kessler RC, Berglund P, Demler O, Jin R, Merikangas KR, Walters EE: Lifetime prevalence and age-of-onset distributions of DSM-IV disorders in the National Comorbidity Survey Replication. Arch Gen Psychiatry 2005;62:593-602.

$>$ Geller DA: Obsessive-compulsive and spectrum disorders in children and adolescents. Psychiatr Clin North Am 2006;29:353-370.
10 Geller DA, Biederman J, Jones J, Shapiro S, Schwartz S, Park KS: Obsessive-compulsive disorder in children and adolescents: a review. Harv Rev Psychiatry 1998;5:260-273.

-11 Heyman I, Fombonne E, Simmons H, Ford T, Meltzer H, Goodman R: Prevalence of obsessive-compulsive disorder in the British nationwide survey of child mental health. Int Rev Psychiatry 2003;15:178-184.

12 Mataix-Cols D, Marks IM, Greist JH, Kobak KA, Baer L: Obsessive-compulsive symptom dimensions as predictors of compliance with and response to behaviour therapy: results from a controlled trial. Psychother Psychosom 2002;71:255-262.

13 Stewart SE, Geller DA, Jenike M, Pauls D, Shaw D, Mullin B, Faraone SV: Long-term outcome of pediatric obsessive-compulsive disorder: a meta-analysis and qualitative review of the literature. Acta Psychiatr Scand 2004;110:4-13.

14 Torres AR, Prince MJ, Bebbington PE, Bhugra D, Brugha TS, Farrell M, Jenkins R, Lewis $\mathrm{G}$, Meltzer $\mathrm{H}$, Singleton N: Obsessivecompulsive disorder: prevalence, comorbidity, impact, and help-seeking in the British National Psychiatric Morbidity Survey of 2000. Am J Psychiatry 2006;163:1978-1985.

15 Baxter LR Jr, Phelps ME, Mazziotta JC, Guze $\mathrm{BH}$, Schwartz JM, Selin CE: Local cerebral glucose metabolic rates in obsessive-compulsive disorder: a comparison with rates in unipolar depression and in normal controls. Arch Gen Psychiatry 1987;44:211-218.

16 Baxter LR Jr, Schwartz JM, Mazziotta JC, Phelps ME, Pahl JJ, Guze BH, Fairbanks L: Cerebral glucose metabolic rates in nondepressed patients with obsessive-compulsive disorder. Am J Psychiatry 1988;145:15601563.
17 Swedo SE, Schapiro MB, Grady CL, Cheslow DL, Leonard HL, Kumar A, Friedland R, Rapoport SI, Rapoport JL: Cerebral glucose metabolism in childhood-onset obsessivecompulsive disorder. Arch Gen Psychiatry 1989;46:518-523

-18 Machlin SR, Harris GJ, Pearlson GD, HoehnSaric R, Jeffery P, Camargo EE: Elevated medial-frontal cerebral blood flow in obsessivecompulsive patients: a SPECT study. Am J Psychiatry 1991;148:1240-1242.

19 Belliveau JW, Kennedy DN Jr, McKinstry RC, Buchbinder BR, Weisskoff RM, Cohen MS, Vevea JM, Brady TJ, Rosen BR: Functional mapping of the human visual cortex by magnetic resonance imaging. Science 1991;254:716-719.

20 Bandettini PA, Wong EC, Hinks RS, Tikofsky RS, Hyde JS: Time course EPI of human brain function during task activation. Magn Reson Med 1992;25:390-397.

-21 Kwong KK, Belliveau JW, Chesler DA, Goldberg IE, Weisskoff RM, Poncelet BP, Kennedy DN, Hoppel BE, Cohen MS, Turner R: Dynamic magnetic resonance imaging of human brain activity during primary sensory stimulation. Proc Natl Acad Sci USA 1992; 89:5675-5679.

22 Ogawa S, Tank DW, Menon R, Ellermann JM, Kim SG, Merkle H, Ugurbil K: Intrinsic signal changes accompanying sensory stimulation: functional brain mapping with magnetic resonance imaging. Proc Natl Acad Sci USA 1992;89:5951-5955. 
-23 Baxter LR Jr, Schwartz JM, Bergman KS, Szuba MP, Guze BH, Mazziotta JC, Alazraki A, Selin CE, Ferng HK, Munford P: Caudate glucose metabolic rate changes with both drug and behavior therapy for obsessivecompulsive disorder. Arch Gen Psychiatry 1992;49:681-689.

-24 Hoehn-Saric R, Pearlson GD, Harris GJ, Machlin SR, Camargo EE: Effects of fluoxetine on regional cerebral blood flow in obsessive-compulsive patients. Am J Psychiatry 1991; 148:1243-1245.

-25 Swedo SE, Pietrini P, Leonard HL, Schapiro MB, Rettew DC, Goldberger EL, Rapoport SI, Rapoport JL, Grady CL: Cerebral glucose metabolism in childhood-onset obsessivecompulsive disorder: revisualization during pharmacotherapy. Arch Gen Psychiatry 1992;49:690-694.

-26 Cottraux J, Gérard D, Cinotti L, Froment JC, Deiber MP, le Bars D, Galy G, Millet P, Labbé C, Lavenne F, Bouvard M, Mauguière F: A controlled positron emission tomography study of obsessive and neutral auditory stimulation in obsessive-compulsive disorder with checking rituals. Psychiatry Res 1996; 60:101-112.

-27 Jenike MA, Breiter HC, Baer L, Kennedy DN, Savage CR, Olivares MJ, O’Sullivan RL, Shera DM, Rauch SL, Keuthen N, Rosen BR, Caviness VS, Filipek PA: Cerebral structural abnormalities in obsessive-compulsive disorder: a quantitative morphometric magnetic resonance imaging study. Arch Gen Psychiatry 1996;53:625-632.

-28 McGuire PK, Bench CJ, Frith CD, Marks IM, Frackowiak RS, Dolan RJ: Functional anatomy of obsessive-compulsive phenomena. $\mathrm{Br}$ J Psychiatry 1994;164:459-468.

-29 Rauch SL, Jenike MA, Alpert NM, Baer L, Breiter HC, Savage CR, Fischman AJ: Regional cerebral blood flow measured during symptom provocation in obsessive-compulsive disorder using oxygen 15-labeled carbon dioxide and positron emission tomography. Arch Gen Psychiatry 1994;51:62-70.

-30 Zohar J, Insel TR, Berman KF, Foa EB, Hill JL, Weinberger DR: Anxiety and cerebral blood flow during behavioral challenge: dissociation of central from peripheral and subjective measures. Arch Gen Psychiatry 1989; 46:505-510.

>31 Savage CR, Weilburg JB, Duffy FH, Baer L, Shera DM, Jenike MA: Low-level sensory processing in obsessive-compulsive disorder: an evoked potential study. Biol Psychiatry 1994;35:247-252.

\32 Towey J, Bruder G, Tenke C, Leite P, DeCaria C, Friedman D, Hollander E: Event-related potential and clinical correlates of neurodysfunction in obsessive-compulsive disorder. Psychiatry Res 1993;49:167-181.

-33 Garber HJ, Ananth JV, Chiu LC, Griswold VJ, Oldendorf WH: Nuclear magnetic resonance study of obsessive-compulsive disorder. Am J Psychiatry 1989;146:1001-1005.
34 Ebert D, Speck O, König A, Berger M, Hennig J, Hohagen F: ${ }^{1} \mathrm{H}$-magnetic resonance spectroscopy in obsessive-compulsive disorder: evidence for neuronal loss in the cingulate gyrus and the right striatum. Psychiatry Res 1997;74:173-176.

35 Perani D, Colombo C, Bressi S, Bonfanti A, Grassi F, Scarone S, Bellodi L, Smeraldi E, Fazio F: $\left[{ }^{18} \mathrm{~F}\right]$ FDG PET study in obsessivecompulsive disorder: a clinical/metabolic correlation study after treatment. Br J Psychiatry 1995;166:244-250.

36 Galderisi S, Mucci A, Catapano F, D’Amato AC, Maj M: Neuropsychological slowness in obsessive-compulsive patients: is it confined to tests involving the fronto-subcortical systems? Br J Psychiatry 1995;167:394-398.

37 Ursu S, Stenger VA, Shear MK, Jones MR, Carter CS: Overactive action monitoring in obsessive-compulsive disorder: evidence from functional magnetic resonance imaging. Psychol Sci 2003;14:347-353.

38 Fitzgerald KD, Welsh RC, Gehring WJ, Abelson JL, Himle JA, Liberzon I, Taylor SF: Error-related hyperactivity of the anterior cingulate cortex in obsessive-compulsive disorder. Biol Psychiatry 2005;57:287-294.

39 Maltby N, Tolin DF, Worhunsky P, O’Keefe TM, Kiehl KA: Dysfunctional action monitoring hyperactivates frontal-striatal circuits in obsessive-compulsive disorder: an event-related fMRI study. Neuroimage 2005; 24:495-503.

-40 Nakao T, Nakagawa A, Yoshiura T, Nakatani E, Nabeyama M, Yoshizato C, Kudoh A, Tada K, Yoshioka K, Kawamoto M: A functional MRI comparison of patients with obsessive-compulsive disorder and normal controls during a Chinese character Stroop task. Psychiatry Res 2005;139:101-114.

41 Nabeyama M, Nakagawa A, Yoshiura T, Nakao T, Nakatani E, Togao O, Yoshizato C, Yoshioka K, Tomita M, Kanba S: Functional MRI study of brain activation alterations in patients with obsessive-compulsive disorder after symptom improvement. Psychiatry Res 2008;163:236-247.

42 Viard A, Flament MF, Artiges E, Dehaene S, Naccache L, Cohen D, Mazet P, Mouren MC, Martinot JL: Cognitive control in childhood-onset obsessive-compulsive disorder: a functional MRI study. Psychol Med 2005; 35:1007-1017.

43 Adler CM, McDonough-Ryan P, Sax KW Holland SK, Arndt S, Strakowski SM: fMRI of neuronal activation with symptom provocation in unmedicated patients with obsessive compulsive disorder. J Psychiatr Res 2000;34:317-324.

44 Breiter HC, Rauch SL: Functional MRI and the study of OCD: from symptom provocation to cognitive-behavioral probes of cortico-striatal systems and the amygdala. Neuroimage 1996;4:S127-S138.
45 Saxena S, Brody AL, Schwartz JM, Baxter LR: Neuroimaging and frontal-subcortical circuitry in obsessive-compulsive disorder. Br J Psychiatry Suppl 1998;35:26-37.

46 Levy R, Goldman-Rakic PS: Segregation of working memory functions within the dorsolateral prefrontal cortex. Exp Brain Res 2000;133:23-32.

47 Petrides M: Specialized systems for the processing of mnemonic information within the primate frontal cortex. Philos Trans R Soc Lond B Biol Sci 1996;351:1455-1461, discussion 1461-1462.

48 Manoach DS, White NS, Lindgren KA, Heckers S, Coleman MJ, Dubal S, Holzman PS: Hemispheric specialization of the lateral prefrontal cortex for strategic processing during spatial and shape working memory. Neuroimage 2004;21:894-903.

49 Petrides M: Frontal lobes and behaviour. Curr Opin Neurobiol 1994;4:207-211.

-50 Burgess PW, Veitch E, de Lacy Costello A, Shallice T: The cognitive and neuroanatomical correlates of multitasking. Neuropsychologia 2000;38:848-863.

51 Bunge SA, Kahn I, Wallis JD, Miller EK, Wagner AD: Neural circuits subserving the retrieval and maintenance of abstract rules. J Neurophysiol 2003;90:3419-3428.

52 Menon V, Mackenzie K, Rivera SM, Reiss AL: Prefrontal cortex involvement in processing incorrect arithmetic equations: evidence from event-related fMRI. Hum Brain Mapp 2002;16:119-130.

53 van den Heuvel OA, Veltman DJ, Groenewegen HJ, Cath DC, van Balkom AJLM, van Hartskamp J, Barkhof F, van Dyck R: Frontal-striatal dysfunction during planning in obsessive-compulsive disorder. Arch Gen Psychiatry 2005;62:301-309.

54 Gu BM, Park JY, Kang DH, Lee SJ, Yoo SY, Jo HJ, Choi CH, Lee JM, Kwon JS: Neural correlates of cognitive inflexibility during taskswitching in obsessive-compulsive disorder. Brain 2008;131:155-164.

55 van der Wee NJA, Ramsey NF, Jansma JM, Denys DA, van Megen HJGM, Westenberg HMG, Kahn RS: Spatial working memory deficits in obsessive compulsive disorder are associated with excessive engagement of the medial frontal cortex. Neuroimage 2003;20: 2271-2280.

56 Nakao T, Nakagawa A, Nakatani E, Nabeyama M, Sanematsu H, Yoshiura T, Togao O, Tomita M, Masuda Y, Yoshioka K, Kuroki T, Kanba S: Working memory dysfunction in obsessive-compulsive disorder: a neuropsychological and functional MRI study. J Psychiatr Res 2009;43:784-791.

57 Nakao T, Nakagawa A, Yoshiura T, Nakatani E, Nabeyama M, Sanematsu H, Togao O, Yoshioka K, Tomita M, Kuroki T, Kanba S: Duration effect of obsessive-compulsive disorder on cognitive function: a functional MRI study. Depress Anxiety 2009;26:814-823. 
-58 Levine JB, Gruber SA, Baird AA, YurgelunTodd D: Obsessive-compulsive disorder among schizophrenic patients: an exploratory study using functional magnetic resonance imaging data. Compr Psychiatry 1998; 39:308-311.

-59 Aouizerate B, Guehl D, Cuny E, Rougier A, Bioulac B, Tignol J, Burbaud P: Pathophysiology of obsessive-compulsive disorder: a necessary link between phenomenology, neuropsychology, imagery and physiology. Prog Neurobiol 2004;72:195-221.

60 Breiter HC, Rauch SL, Kwong KK, Baker JR, Weisskoff RM, Kennedy DN, Kendrick AD, Davis TL, Jiang A, Cohen MS, Stern CE, Belliveau JW, Baer L, O'Sullivan RL, Savage CR, Jenike MA, Rosen BR: Functional magnetic resonance imaging of symptom provocation in obsessive-compulsive disorder. Arch Gen Psychiatry 1996;53:595-606.

-61 McDougle CJ, Epperson CN, Pelton GH, Wasylink S, Price LH: A double-blind, placebo-controlled study of risperidone addition in serotonin reuptake inhibitor-refractory obsessive-compulsive disorder. Arch Gen Psychiatry 2000;57:794-801.

-62 Rogers RD, Blackshaw AJ, Middleton HC, Matthews K, Hawtin K, Crowley C, Hopwood A, Wallace C, Deakin JF, Sahakian BJ, Robbins TW: Tryptophan depletion impairs stimulus-reward learning while methylphenidate disrupts attentional control in healthy young adults: implications for the monoaminergic basis of impulsive behaviour. Psychopharmacology 1999;146:482-491.

-63 Schultz W: Predictive reward signal of dopamine neurons. J Neurophysiol 1998;80:1-27.

64 Abbruzzese M, Ferri S, Scarone S: The selective breakdown of frontal functions in patients with obsessive-compulsive disorder and in patients with schizophrenia: a double dissociation experimental finding. Neuropsychologia 1997;35:907-912.

- 65 Cavedini P, Riboldi G, D’Annucci A, Belotti P, Cisima M, Bellodi L: Decision-making heterogeneity in obsessive-compulsive disorder: ventromedial prefrontal cortex function predicts different treatment outcomes. Neuropsychologia 2002;40:205-211.

-66 Hermesh H, Zohar J, Weizman A, Voet H, Gross-Isseroff R: Orbitofrontal cortex dysfunction in obsessive-compulsive disorder? 2. Olfactory quality discrimination in obsessive-compulsive disorder. Eur Neuropsychopharmacol 1999;9:415-420.

-67 Nielen MMA, Veltman DJ, de Jong R, Mulder $G$, den Boer JA: Decision making performance in obsessive compulsive disorder. J Affect Disord 2002;69:257-260.

68 Kim JJ, Lee MC, Kim J, Kim IY, Kim SI, Han $\mathrm{MH}$, Chang KH, Kwon JS: Grey matter abnormalities in obsessive-compulsive disorder: statistical parametric mapping of segmented magnetic resonance images. $\mathrm{Br} \mathrm{J}$ Psychiatry 2001;179:330-334.
69 Pujol J, Soriano-Mas C, Alonso P, Cardoner N, Menchon JM, Deus J, Vallejo J: Mapping structural brain alterations in obsessivecompulsive disorder. Arch Gen Psychiatry 2004;61:720-730.

70 Lacerda ALT, Dalgalarrondo P, Caetano D, Camargo EE, Etchebehere ECSC, Soares JC: Elevated thalamic and prefrontal regional cerebral blood flow in obsessive-compulsive disorder: a SPECT study. Psychiatry Res 2003;123:125-134.

-71 Busatto GF, Zamignani DR, Buchpiguel CA, Garrido GE, Glabus MF, Rocha ET, Maia AF, Rosario-Campos MC, Campi Castro C, Furuie SS, Gutierrez MA, McGuire PK, Miguel EC: A voxel-based investigation of regional cerebral blood flow abnormalities in obsessive-compulsive disorder using single photon emission computed tomography (SPECT). Psychiatry Res 2000;99:15-27.

72 van den Heuvel OA, Veltman DJ, Groenewegen HJ, Dolan RJ, Cath DC, Boellaard R, Mesina CT, van Balkom AJLM, van Oppen $P$, Witter MP, Lammertsma AA, van Dyck R: Amygdala activity in obsessive-compulsive disorder with contamination fear: a study with oxygen-15 water positron emission tomography. Psychiatry Res 2004;132:225237.

73 Remijnse PL, Nielen MMA, van Balkom AJLM, Cath DC, van Oppen P, Uylings HBM, Veltman DJ: Reduced orbitofrontalstriatal activity on a reversal learning task in obsessive-compulsive disorder. Arch Gen Psychiatry 2006;63:1225-1236.

74 Rauch SL, Wedig MM, Wright CI, Martis B, McMullin KG, Shin LM, Cannistraro PA, Wilhelm S: Functional magnetic resonance imaging study of regional brain activation during implicit sequence learning in obsessive-compulsive disorder. Biol Psychiatry 2007;61:330-336.

75 Baxter LR Jr: Basal ganglia systems in ritualistic social displays: reptiles and humans function and illness. Physiol Behav 2003;79: 451-460.

76 Remijnse PL, Nielen MMA, van Balkom AJLM, Hendriks GJ, Hoogendijk WJ, Uylings HBM, Veltman DJ: Differential frontal-striatal and paralimbic activity during reversal learning in major depressive disorder and obsessive-compulsive disorder. Psychol Med 2009;39:1503-1518.

77 Crespo-Facorro B, Cabranes JA, Lopez-Ibor Alcocer MI, Paya B, Fernandez Perez C, Encinas M, Ayuso Mateos JL, Lopez-Ibor JJ Jr: Regional cerebral blood flow in obsessivecompulsive patients with and without a chronic tic disorder: a SPECT study. Eur Arch Psychiatry Clin Neurosci 1999;249:156-161.

78 Lucey JV, Costa DC, Blanes T, Busatto GF, Pilowsky LS, Takei N, Marks IM, Ell PJ, Kerwin RW: Regional cerebral blood flow in obsessive-compulsive disordered patients at rest: differential correlates with obsessivecompulsive and anxious-avoidant dimensions. Br J Psychiatry 1995;167:629-634.
79 Roth RM, Saykin AJ, Flashman LA, Pixley HS, West JD, Mamourian AC: Event-related functional magnetic resonance imaging of response inhibition in obsessive-compulsive disorder. Biol Psychiatry 2007;62:901-909.

80 Ullsperger M, von Cramon DY: Subprocesses of performance monitoring: a dissociation of error processing and response competition revealed by event-related fMRI and ERPs. Neuroimage 2001;14:1387-1401.

-81 Garavan H, Ross TJ, Kaufman J, Stein EA: A midline dissociation between error-processing and response-conflict monitoring. Neuroimage 2003;20:1132-1139.

82 Yücel M, Harrison BJ, Wood SJ, Fornito A, Wellard RM, Pujol J, Clarke K, Phillips ML, Kyrios M, Velakoulis D, Pantelis C: Functional and biochemical alterations of the medial frontal cortex in obsessive-compulsive disorder. Arch Gen Psychiatry 2007;64:946955 .

83 Buckner RL, Raichle ME, Petersen SE: Dissociation of human prefrontal cortical areas across different speech production tasks and gender groups. J Neurophysiol 1995;74: 2163-2173.

84 Mummery CJ, Patterson K, Hodges JR, Wise RJ: Generating 'tiger' as an animal name or a word beginning with $\mathrm{T}$ : differences in brain activation. Proc Biol Sci 1996;263:989-995.

85 Pujol J, Vendrell P, Deus J, Kulisevsky J, Martí-Vilalta JL, García C, Junqué C, Capdevila A: Frontal lobe activation during word generation studied by functional MRI. Acta Neurol Scand 1996;93:403-410.

86 Cuenod CA, Bookheimer SY, Hertz-Pannier L, Zeffiro TA, Theodore WH, le Bihan D: Functional MRI during word generation, using conventional equipment: a potential tool for language localization in the clinical environment. Neurology 1995;45:1821-1827.

-87 Rueckert L, Appollonio I, Grafman J, Jezzard P, Johnson R Jr, le Bihan D, Turner R: Magnetic resonance imaging functional activation of left frontal cortex during covert word production. J Neuroimaging 1994;4:67-70.

88 Yetkin FZ, Hammeke TA, Swanson SJ, Morris GL, Mueller WM, McAuliffe TL, Haughton VM: A comparison of functional MR activation patterns during silent and audible language tasks. AJNR Am J Neuroradiol 1995; 16:1087-1092.

89 Yurgelun-Todd DA, Waternaux CM, Cohen BM, Gruber SA, English CD, Renshaw PF: Functional magnetic resonance imaging of schizophrenic patients and comparison subjects during word production. Am J Psychiatry 1996;153:200-205.

90 Christensen KJ, Kim SW, Dysken MW, Hoover KM: Neuropsychological performance in obsessive-compulsive disorder. Biol Psychiatry 1992;31:4-18.

91 Otto MW: Normal and abnormal information processing: a neuropsychological perspective on obsessive-compulsive disorder. Psychiatr Clin North Am 1992;15:825-848. 
\$2 Henseler I, Gruber O, Kraft S, Krick C, Reith W, Falkai P: Compensatory hyperactivations as markers of latent working memory dysfunctions in patients with obsessive-compulsive disorder: an fMRI study. J Psychiatry Neurosci 2008;33:209-215.

$\checkmark 93$ Lázaro L, Caldú X, Junqué C, Bargalló N, Andrés S, Morer A, Castro-Fornieles J: Cerebral activation in children and adolescents with obsessive-compulsive disorder before and after treatment: a functional MRI study. J Psychiatr Res 2008;42:10511059.

94 Jung WH, Gu BM, Kang DH, Park JY, Yoo SY, Choi CH, Lee JM, Kwon JS: BOLD response during visual perception of biological motion in obsessive-compulsive disorder: an fMRI study using the dynamic point-light animation paradigm. Eur Arch Psychiatry Clin Neurosci 2009;259:46-54.

95 Simpson S, Baldwin B: Neuropsychiatry and SPECT of an acute obsessive-compulsive syndrome patient. Br J Psychiatry 1995; 166:390-392.

$\$ 96$ Berthier ML, Kulisevsky J, Gironell A, Heras JA: Obsessive-compulsive disorder associated with brain lesions: clinical phenomenology, cognitive function, and anatomic correlates. Neurology 1996;47:353-361.

97 Hendler T, Goshen E, Tadmor R, Lustig M, Zwas ST, Zohar J: Evidence for striatal modulation in the presence of fixed cortical injury in obsessive-compulsive disorder (OCD). Eur Neuropsychopharmacol 1999; 9:371-376.

$\$ 98$ Walker SC, Robbins TW, Roberts AC: Differential contributions of dopamine and serotonin to orbitofrontal cortex function in the marmoset. Cereb Cortex 2009;19:889898.

\$9 Koepp MJ, Gunn RN, Lawrence AD, Cunningham VJ, Dagher A, Jones T, Brooks DJ, Bench CJ, Grasby PM: Evidence for striatal dopamine release during a video game. Nature 1998;393:266-268.

100 Schilman EA, Klavir O, Winter C, Sohr R, Joel D: The role of the striatum in compulsive behavior in intact and orbitofrontalcortex-lesioned rats: possible involvement of the serotonergic system. Neuropsychopharmacology 2010;35:1026-1039.

- 101 van der Wee NJ, Stevens H, Hardeman JA, Mandl RC, Denys DA, van Megen HJ, Kahn RS, Westenberg HM: Enhanced dopamine transporter density in psychotropic-naive patients with obsessive-compulsive disorder shown by $\left[{ }^{123} \mathrm{I}\right] \beta$-CIT SPECT. Am J Psychiatry 2004;161:2201-2206.

102 Denys D, van der Wee N, Janssen J, de Geus F, Westenberg HGM: Low level of dopaminergic $\mathrm{D}_{2}$ receptor binding in obsessivecompulsive disorder. Biol Psychiatry 2004; 55:1041-1045.

-103 Alexander GE, DeLong MR, Strick PL: Parallel organization of functionally segregated circuits linking basal ganglia and cortex. Annu Rev Neurosci 1986;9:357-381.
104 Knopman D, Nissen MJ: Procedural learning is impaired in Huntington's disease: evidence from the serial reaction time task. Neuropsychologia 1991;29:245-254.

105 Aylward EH, Harris GJ, Hoehn-Saric R, Barta PE, Machlin SR, Pearlson GD: Normal caudate nucleus in obsessive-compulsive disorder assessed by quantitative neuroimaging. Arch Gen Psychiatry 1996;53: 577-584.

106 Robinson D, Wu H, Munne RA, Ashtari M, Alvir JM, Lerner G, Koreen A, Cole K, Bogerts B: Reduced caudate nucleus volume in obsessive-compulsive disorder. Arch Gen Psychiatry 1995;52:393-398.

107 Rubin RT, Villanueva-Meyer J, Ananth J, Trajmar PG, Mena I: Regional xenon 133 cerebral blood flow and cerebral technetium 99m HMPAO uptake in unmedicated patients with obsessive-compulsive disorder and matched normal control subjects: determination by high-resolution singlephoton emission computed tomography. Arch Gen Psychiatry 1992;49:695-702.

108 Saxena S, Brody AL, Maidment KM, Smith EC, Zohrabi N, Katz E, Baker SK, Baxter LR Jr: Cerebral glucose metabolism in obsessive-compulsive hoarding. Am J Psychiatry 2004;161:1038-1048.

109 Deckersbach T, Savage CR, Curran T, Bohne A, Wilhelm S, Baer L, Jenike MA, Rauch SL: A study of parallel implicit and explicit information processing in patients with obsessive-compulsive disorder. Am J Psychiatry 2002;159:1780-1782.

110 Rauch SL, Savage CR: Neuroimaging and neuropsychology of the striatum: bridging basic science and clinical practice. Psychiatr Clin North Am 1997;20:741-768.

111 Nakao T, Nakagawa A, Yoshiura T, Nakatani E, Nabeyama M, Yoshizato C, Kudoh A, Tada K, Yoshioka K, Kawamoto M, Togao O, Kanba S: Brain activation of patients with obsessive-compulsive disorder during neuropsychological and symptom provocation tasks before and after symptom improvement: a functional magnetic resonance imaging study. Biol Psychiatry 2005;57:901-910

-112 Benkelfat C, Nordahl TE, Semple WE, King AC, Murphy DL, Cohen RM: Local cerebral glucose metabolic rates in obsessive-compulsive disorder: patients treated with clomipramine. Arch Gen Psychiatry 1990;47: 840-848.

113 Rauch SL, Jenike MA: Neurobiological models of obsessive-compulsive disorder. Psychosomatics 1993;34:20-32.

114 Rauch SL, Savage CR, Alpert NM, Dougherty D, Kendrick A, Curran T, Brown HD, Manzo P, Fischman AJ, Jenike MA: Probing striatal function in obsessive-compulsive disorder: a PET study of implicit sequence learning. J Neuropsychiatry Clin Neurosci 1997;9:568-573.
115 Purcell R, Maruff P, Kyrios M, Pantelis C: Cognitive deficits in obsessive-compulsive disorder on tests of frontal-striatal function. Biol Psychiatry 1998;43:348-357.

116 Purcell R, Maruff P, Kyrios M, Pantelis C: Neuropsychological deficits in obsessivecompulsive disorder: a comparison with unipolar depression, panic disorder, and normal controls. Arch Gen Psychiatry 1998;55:415-423.

117 Mataix-Cols D, Junqué C, Sànchez-Turet M, Vallejo J, Verger K, Barrios M: Neuropsychological functioning in a subclinical obsessive-compulsive sample. Biol Psychiatry 1999;45:898-904.

118 Schmidtke K, Schorb A, Winkelmann G, Hohagen F: Cognitive frontal lobe dysfunction in obsessive-compulsive disorder. Biol Psychiatry 1998;43:666-673.

119 Veale DM, Sahakian BJ, Owen AM, Marks IM: Specific cognitive deficits in tests sensitive to frontal lobe dysfunction in obsessive-compulsive disorder. Psychol Med 1996;26:1261-1269.

120 Keith Berg W, Byrd D: The Tower of London spatial problem-solving task: enhancing clinical and research implementation. J Clin Exp Neuropsychol 2002;24:586-604.

- 121 Cahill L, Haier RJ, Fallon J, Alkire MT, Tang C, Keator D, Wu J, McGaugh JL: Amygdala activity at encoding correlated with long-term, free recall of emotional information. Proc Natl Acad Sci USA 1996; 93:8016-8021.

- 122 Corbetta M, Shulman GL, Miezin FM, Petersen SE: Superior parietal cortex activation during spatial attention shifts and visual feature conjunction. Science 1995;270: 802-805.

123 Courchesne E, Townsend J, Akshoomoff NA, Saitoh O, Yeung-Courchesne R, Lincoln AJ, James HE, Haas RH, Schreibman L, Lau L: Impairment in shifting attention in autistic and cerebellar patients. Behav Neurosci 1994;108:848-865.

124 Kim SG, Ugurbil K, Strick PL: Activation of a cerebellar output nucleus during cognitive processing. Science 1994;265:949-951.

125 Le TH, Pardo JV, Hu X: 4 T-fMRI study of nonspatial shifting of selective attention: cerebellar and parietal contributions. J Neurophysiol 1998;79:1535-1548.

126 Schmahmann JD, Pandya DN: Prefrontal cortex projections to the basilar pons in rhesus monkey: implications for the cerebellar contribution to higher function. Neurosci Lett 1995;199:175-178.

127 Schmahmann JD, Pandya DN: Anatomical investigation of projections to the basis pontis from posterior parietal association cortices in rhesus monkey. J Comp Neurol 1989;289:53-73.

128 Schmahmann JD, Pandya DN: Prelunate, occipitotemporal, and parahippocampal projections to the basis pontis in rhesus monkey. J Comp Neurol 1993;337:94-112. 
129 Vilensky JA, van Hoesen GW: Corticopontine projections from the cingulate cortex in the rhesus monkey. Brain Res 1981;205: 391-395.

130 Schmahmann JD, Sherman JC: The cerebellar cognitive affective syndrome. Brain 1998;121(pt 4):561-579.

-131 Page LA, Rubia K, Deeley Q, Daly E, Toal F, Mataix-Cols D, Giampietro V, Schmitz N, Murphy DGM: A functional magnetic resonance imaging study of inhibitory control in obsessive-compulsive disorder. Psychiatry Res 2009;174:202-209.

- 132 Sanematsu H, Nakao T, Yoshiura T, Nabeyama M, Togao O, Tomita M, Masuda $\mathrm{Y}$, Nakatani E, Nakagawa A, Kanba S: Predictors of treatment response to fluvoxamine in obsessive-compulsive disorder: an fMRI study. J Psychiatr Res 2010;44:193-200.

133 Kang DH, Kwon JS, Kim JJ, Youn T, Park HJ, Kim MS, Lee DS, Lee MC: Brain glucose metabolic changes associated with neuropsychological improvements after 4 months of treatment in patients with obsessivecompulsive disorder. Acta Psychiatr Scand 2003;107:291-297.

134 Rauch SL, Baxter LR: Neuroimaging of OCD and related disorders; in Jenike MA, Baer L, Minichiello WE (eds): ObsessiveCompulsive Disorders. Theory and Management. St. Louis, Mosby, 1998, pp 289317.

- 135 Nordahl TE, Benkelfat C, Semple WE, Gross M, King AC, Cohen RM: Cerebral glucose metabolic rates in obsessive compulsive disorder. Neuropsychopharmacology 1989;2:23-28.

- 136 Brody AL, Saxena S, Schwartz JM, Stoessel PW, Maidment K, Phelps ME, Baxter LR Jr: FDG-PET predictors of response to behavioral therapy and pharmacotherapy in obsessive-compulsive disorder. Psychiatry Res 1998;84:1-6.

-137 Schwartz JM, Stoessel PW, Baxter LR Jr, Martin KM, Phelps ME: Systematic changes in cerebral glucose metabolic rate after successful behavior modification treatment of obsessive-compulsive disorder. Arch Gen Psychiatry 1996;53:109-113.

-138 Rauch SL, Dougherty DD, Cosgrove GR, Cassem EH, Alpert NM, Price BH, Nierenberg AA, Mayberg HS, Baer L, Jenike MA, Fischman AJ: Cerebral metabolic correlates as potential predictors of response to anterior cingulotomy for obsessive compulsive disorder. Biol Psychiatry 2001;50:659-667.

-139 Saxena S, Brody AL, Maidment KM, Dunkin JJ, Colgan M, Alborzian S, Phelps ME, Baxter LR Jr: Localized orbitofrontal and subcortical metabolic changes and predictors of response to paroxetine treatment in obsessive-compulsive disorder. Neuropsychopharmacology 1999;21:683-693.

140 Deckersbach T, Dougherty DD, Rauch SL: Functional imaging of mood and anxiety disorders. J Neuroimaging 2006;16:1-10.
141 Mataix-Cols D, Rosario-Campos MC, Leckman JF: A multidimensional model of obsessive-compulsive disorder. Am J Psychiatry 2005;162:228-238.

142 Miguel EC, Leckman JF, Rauch S, do Rosario-Campos MC, Hounie AG, Mercadante MT, Chacon P, Pauls DL: Obsessive-compulsive disorder phenotypes: implications for genetic studies. Mol Psychiatry 2005; 10: 258-275.

143 Leckman JF, Grice DE, Boardman J, Zhang $\mathrm{H}$, Vitale A, Bondi C, Alsobrook J, Peterson BS, Cohen DJ, Rasmussen SA, Goodman WK, McDougle CJ, Pauls DL: Symptoms of obsessive-compulsive disorder. Am J Psychiatry 1997;154:911-917.

144 Baer L: Factor analysis of symptom subtypes of obsessive-compulsive disorder and their relation to personality and tic disorders. J Clin Psychiatry 1994;55(suppl): $18-23$.

145 Summerfeldt LJ, Richter MA, Antony MM, Swinson RP: Symptom structure in obsessive-compulsive disorder: a confirmatory factor-analytic study. Behav Res Ther 1999; 37:297-311.

146 Mataix-Cols D, Rauch SL, Baer L, Eisen JL, Shera DM, Goodman WK, Rasmussen SA, Jenike MA: Symptom stability in adult obsessive-compulsive disorder: data from a naturalistic two-year follow-up study. Am J Psychiatry 2002;159:263-268.

147 Alsobrook JP 2nd, Leckman JF, Goodman WK, Rasmussen SA, Pauls DL: Segregation analysis of obsessive-compulsive disorder using symptom-based factor scores. Am J Med Genet 1999;88:669-675.

148 Leckman JF, Pauls DL, Zhang H, RosarioCampos MC, Katsovich L, Kidd KK, Pakstis AJ, Alsobrook JP, Robertson MM, McMahon WM, Walkup JT, van de Wetering BJM, King RA, Cohen DJ: Obsessive-compulsive symptom dimensions in affected sibling pairs diagnosed with Gilles de la Tourette syndrome. Am J Med Genet B Neuropsychiatr Genet 2003;116B:60-68.

149 Zhang H, Leckman JF, Pauls DL, Tsai CP, Kidd KK, Campos MR: Genomewide scan of hoarding in sib pairs in which both sibs have Gilles de la Tourette syndrome. Am J Hum Genet 2002;70:896-904.

150 Mataix-Cols D, Wooderson S, Lawrence N, Brammer MJ, Speckens A, Phillips ML: Distinct neural correlates of washing, checking, and hoarding symptom dimensions in obsessive-compulsive disorder. Arch Gen Psychiatry 2004;61:564-576.

151 Gilbert AR, Akkal D, Almeida JRC, Mataix-Cols D, Kalas C, Devlin B, Birmaher B, Phillips ML: Neural correlates of symptom dimensions in pediatric obsessive-compulsive disorder: a functional magnetic resonance imaging study. J Am Acad Child Adolesc Psychiatry 2009;48:936-944.
152 Rubia K, Cubillo A, Smith AB, Woolley J, Heyman I, Brammer MJ: Disorder-specific dysfunction in right inferior prefrontal cortex during two inhibition tasks in boys with attention-deficit hyperactivity disorder compared to boys with obsessive-compulsive disorder. Hum Brain Mapp 2010;31: 287-299.

153 Woolley J, Heyman I, Brammer M, Frampton I, McGuire PK, Rubia K: Brain activation in paediatric obsessive compulsive disorder during tasks of inhibitory control. Br J Psychiatry 2008;192:25-31.

154 Rosenberg DR, Keshavan MS, O'Hearn KM, Dick EL, Bagwell WW, Seymour AB, Montrose DM, Pierri JN, Birmaher B: Frontostriatal measurement in treatment-naive children with obsessive-compulsive disorder. Arch Gen Psychiatry 1997;54:824-830.

-155 Szeszko PR, MacMillan S, McMeniman M, Chen S, Baribault K, Lim KO, Ivey J, Rose M, Banerjee SP, Bhandari R, Moore GJ, Rosenberg DR: Brain structural abnormalities in psychotropic drug-naive pediatric patients with obsessive-compulsive disorder. Am J Psychiatry 2004;161:1049-1056.

156 Gilbert AR, Moore GJ, Keshavan MS, Paulson LA, Narula V, Mac Master FP, Stewart $\mathrm{CM}$, Rosenberg DR: Decrease in thalamic volumes of pediatric patients with obsessive-compulsive disorder who are taking paroxetine. Arch Gen Psychiatry 2000;57: 449-456.

157 Austin MP, Mitchell P, Goodwin GM: Cognitive deficits in depression: possible implications for functional neuropathology. $\mathrm{Br} \mathrm{J}$ Psychiatry 2001;178:200-206.

158 Swaab DF, Fliers E, Hoogendijk WJ, Veltman DJ, Zhou JN: Interaction of prefrontal cortical and hypothalamic systems in the pathogenesis of depression. Prog Brain Res 2000;126:369-396.

-159 Saxena S, Brody AL, Ho ML, Alborzian S, Ho MK, Maidment KM, Huang SC, Wu HM, Au SC, Baxter LR Jr: Cerebral metabolism in major depression and obsessivecompulsive disorder occurring separately and concurrently. Biol Psychiatry 2001;50: 159-170.

160 Greisberg S, McKay D: Neuropsychology of obsessive-compulsive disorder: a review and treatment implications. Clin Psychol Rev 2003;23:95-117.

161 Dehaene S, Changeux JP: A hierarchical neuronal network for planning behavior. Proc Natl Acad Sci USA 1997;94:1329313298.

162 Anzai Y, Simon HA: The theory of learning by doing. Psychol Rev 1979;86:124-140.

163 Shallice T: Specific impairments of planning. Philos Trans R Soc Lond B Biol Sci 1982;298:199-209.

164 Baker SC, Rogers RD, Owen AM, Frith CD, Dolan RJ, Frackowiak RS, Robbins TW: Neural systems engaged by planning: a PET study of the Tower of London task. Neuropsychologia 1996;34:515-526. 
-165 Dagher A, Owen AM, Boecker H, Brooks DJ: Mapping the network for planning: a correlational PET activation study with the Tower of London task. Brain 1999;122(pt 10):1973-1987.

166 Owen AM, Doyon J, Petrides M, Evans AC: Planning and spatial working memory: a positron emission tomography study in humans. Eur J Neurosci 1996;8:353-364.

167 Rowe JB, Owen AM, Johnsrude IS, Passingham RE: Imaging the mental components of a planning task. Neuropsychologia 2001; 39:315-327.

168 Morris RG, Ahmed S, Syed GM, Toone BK: Neural correlates of planning ability: frontal lobe activation during the Tower of London test. Neuropsychologia 1993;31:13671378.

-169 Rezai K, Andreasen NC, Alliger R, Cohen G, Swayze V 2nd, O'Leary DS: The neuropsychology of the prefrontal cortex. Arch Neurol 1993;50:636-642.

170 Cazalis F, Valabregue R, Pelegrini-Issac M, Asloun S, Robbins TW, Granon S: Individual differences in prefrontal cortical activation on the Tower of London planning task: implication for effortful processing. Eur J Neurosci 2003;17:2219-2225.

-171 Fincham JM, Carter CS, van Veen V, Stenger VA, Anderson JR: Neural mechanisms of planning: a computational analysis using event-related fMRI. Proc Natl Acad Sci USA 2002;99:3346-3351.
172 Lazeron RH, Rombouts SA, Machielsen WC, Scheltens P, Witter MP, Uylings HB, Barkhof F: Visualizing brain activation during planning: the Tower of London test adapted for functional MR imaging. AJNR Am J Neuroradiol 2000;21:1407-1414.

173 Newman SD, Carpenter PA, Varma S, Just MA: Frontal and parietal participation in problem solving in the Tower of London: fMRI and computational modeling of planning and high-level perception. Neuropsychologia 2003;41:1668-1682.

174 van den Heuvel OA, Groenewegen HJ, Barkhof F, Lazeron RHC, van Dyck R, Veltman DJ: Frontostriatal system in planning complexity: a parametric functional magnetic resonance version of Tower of London task. Neuroimage 2003;18:367-374.

175 Pujol J, Torres L, Deus J, Cardoner N, Pifarré J, Capdevila A, Vallejo J: Functional magnetic resonance imaging study of frontal lobe activation during word generation in obsessive-compulsive disorder. Biol Psychiatry 1999;45:891-897.

176 Ursu S, Carter CS: An initial investigation of the orbitofrontal cortex hyperactivity in obsessive-compulsive disorder: exaggerated representations of anticipated aversive events? Neuropsychologia 2009;47:21452148.

177 Martinot JL, Hardy P, Feline A, Huret JD, Mazoyer B, Attar-Levy D, Pappata S, Syrota A: Left prefrontal glucose hypometabolism in the depressed state: a confirmation. Am J Psychiatry 1990;147:1313-1317.
178 Sawle GV, Hymas NF, Lees AJ, Frackowiak RS: Obsessional slowness: functional studies with positron emission tomography. Brain 1991;114:2191-2202.

179 Rauch SL, Shin LM, Dougherty DD, Alpert NM, Fischman AJ, Jenike MA: Predictors of fluvoxamine response in contamination-related obsessive compulsive disorder: a PET symptom provocation study. Neuropsychopharmacology 2002;27:782-791.

180 Lucey JV, Costa DC, Busatto G, Pilowsky LS, Marks IM, Ell PJ, Kerwin RW: Caudate regional cerebral blood flow in obsessivecompulsive disorder, panic disorder and healthy controls on single photon emission computerised tomography. Psychiatry Res 1997;74:25-33.

181 Bartha R, Stein MB, Williamson PC, Drost DJ, Neufeld RW, Carr TJ, Canaran G, Densmore M, Anderson G, Siddiqui AR: A short echo ${ }^{1} \mathrm{H}$ spectroscopy and volumetric MRI study of the corpus striatum in patients with obsessive-compulsive disorder and comparison subjects. Am J Psychiatry 1998; 155:1584-1591.

182 Alptekin K, Degirmenci B, Kivircik B, Durak H, Yemez B, Derebek E, Tunca Z: Tc99m HMPAO brain perfusion SPECT in drug-free obsessive-compulsive patients without depression. Psychiatry Res 2001; 107:51-56. 